
Elsevier Editorial System(tm) for Electrochimica Acta Manuscript Draft

Manuscript Number: EF15-070R1

Title: Development of label-free impedimetric platform based on new conductive polyaniline polymer and three-dimensional interdigitated electrode array for biosensor applications

Article Type: Research Paper

Keywords: Interdigitated electrode array, DET, PQQ dependent enzyme, polyaniline, biosensor

Corresponding Author: Dr. Edita Voitechovic,

Corresponding Author's Institution: St. Petersburg State University

First Author: Edita Voitechovic

Order of Authors: Edita Voitechovic; Andrey Bratov; Natalija Abramova; Julija Razumiene; Dmitry Kirsanov; Andrey Legin; Dhana Lakshmi; Sergey Piletsky; Michael Whitcombe; P. K. Ivanova-Mitseva

Abstract: Novel label-free impedimetric platform based on a three-dimensional interdigitated electrode array (3D-IDEA) sensor and new conductive polymer as a transducer for oxidoreductases is introduced. This platform is cost-effective, simple to construct and miniaturize. Monomer of conductive polymer $\mathrm{N}-\left(\mathrm{N}\right.$ ', $\mathrm{N}^{\prime}$-diethyldithiocarbamoylethylamidoethyl)aniline (AnD) was deposited onto 3D-IDEA by chemical polymerisation. It was found that the polymer film resistance depends on the redoxpotential of the solution. For the first time polyAnD was used as enzyme immobilisation matrix. Pyrroloquinolinequinone (PQQ) dependent alcohol and glucose dehydrogenases were immobilized on 3D-IDEA covered with polyAnD by two different methods. 3D-IDEA sensors with enzymes, which were immobilised by superficial adsorption on polyAnD layer, showed specific response in the presence of corresponding substrates with $1 \mu \mathrm{M}$ sensitivity. Obtained results revealed that PQQ dependent dehydrogenases can re-oxidize on polyAnD via direct electron transfer (DET) from enzyme active site to the polymer surface. This process can be monitored by methods of electrochemical impedance spectroscopy (EIS) and chronoamperometry. Presented study shows that EIS method gives a useful tool for research of re-oxidation process and interaction of electroactive enzymes with conducting materials giving information required to construct and develop analytical devices. 
From: Dr. Edita Voitechovic Institute of Chemistry St. Petersburg State University Universitetskaya nab. 7/9 199034, St. Petersburg, Russia tel. +78123282835

E-mail: voitechovic.edita@gmail.com

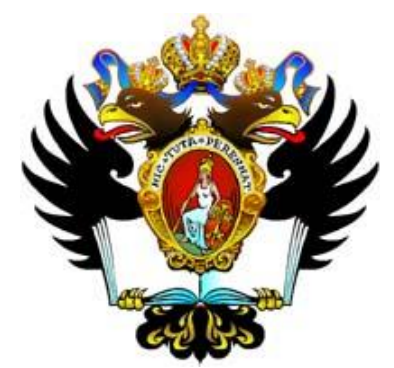

Editorial Office Electrochimica Acta

Dr. Elena Ferapontova

Dear Dr. Elena Ferapontova,

We would like to thank You for giving us an opportunity to revise our submission "Development of labelfree impedimetric platform based on new conductive polyaniline polymer and three dimensional interdigitated electrode array for biosensor applications".

The comments of both Reviewers were very helpful and we are grateful to them for careful reading. We have implemented all their suggestions in the revised version of the manuscript. We are sending the corrected paper for your further consideration. Please contact me if you require further information.

Sincerely yours,

Edita Voitechovic

April 15, 2015 


\section{Graphical Abstract (for review)}

CONDUCTIVE POLYMER LAYER

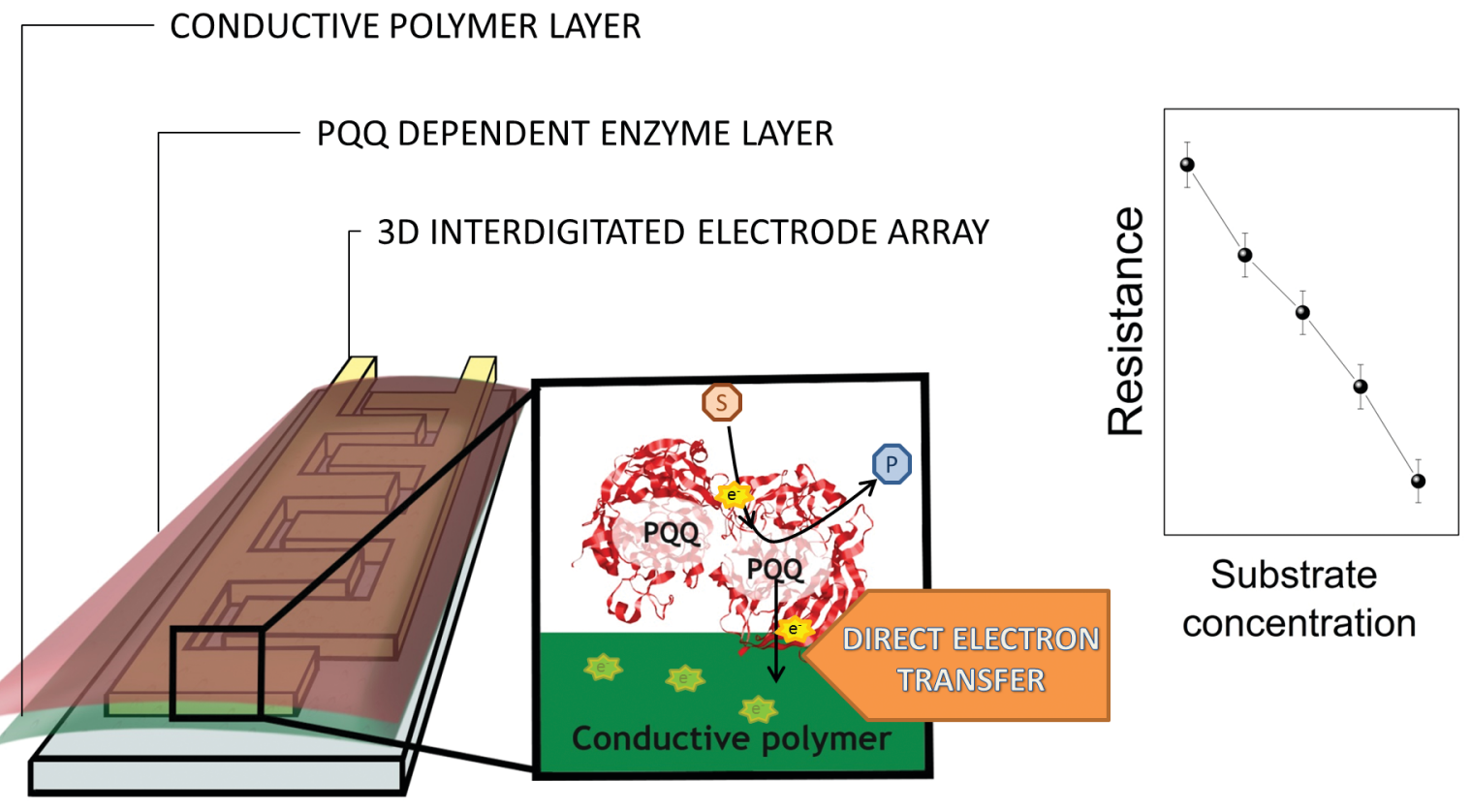


We are thankful to reviewers for their critical comments and interesting questions. The detailed answers for the points raised by referees are provided below.

\section{Reviewer \#2}

\section{The chemical structure of polyAnD should be shown.}

A figure with the chemical structure of polyAnD was added to the manuscript (p.8).

2. In the introduction it is mentioned that poly $\mathrm{AnD}$ has a dithiocarbamate functional unit that can be used for further surface modification. However, it is not clear from the manuscript to what extent this functional unit is utilized in the present work where the enzymes were immobilized by "superficial adsorption". What is the advantage of polyAnD compared to polyaniline (or some other common conducting polymer) in the present work?

Superficial adsorption or physisorption is the most simple and less destructive enzyme immobilization method. However, the biggest problems with this method are either too weak or too strong enzyme globule adhesion or improper enzyme orientation. We expected that such additional modification of aniline may result in a polymer with surface properties facilitating enzyme attachment and coordination. The main advantage of dithiocarbamate functional group is a possibility to modify the polyaniline layer with different monomers by simple UV grafting (P.K. Ivanova-Mitseva, V. Fragkou, D. Lakshmi, M.J. Whitcombe, F. Davis, A. Guerreiro, J.A. Crayston, D.K. Ivanova, P.A. Mitsev, E.V. Piletska, S.A. Piletsky, Conjugated polymers with pendant iniferter units: versatile materials for grafting, Macromolecules, 44 (2011) 1856-1865). This gives opportunity to modify the polymer surface in a desired way. Additionally, it was shown, that polyAnD can be used as molecular imprinted polymer for amperometric determination of some organic compounds. These features seem useful and are more advantageous in comparison with other conducting polymers for construction and directional modification of electrode matrix. However, before trying to optimize polyAnD three-dimensional structure, one should study reactions of enzymes in contact with this polymer. As it is noted in the introduction, this was the principal scope of the present work. Another advantage of polyAnD that was found recently by our colleagues (data are not shown in present article) is that conductivity of polyAnD is less dependent on $\mathrm{pH}$ in comparison with polyaniline and other common conducting polymers. It opens the possibility to design sensors based on conducting polymers which can work in a broad $\mathrm{pH}$ range. Corresponding comment was added to the revised version (p. 6).

3. Since polyAnD was chemically polymerized, how can you control where it is deposited on the 3D-IDEA? SEM pictures before and after deposition could help to illustrate this. 
PolyAnD was deposited onto the whole electrode surface, which was immersed into the polymerization solution. As the polymer has green color, this can be easily controlled by optical microscopy. The electrode surface before (A) and after (B) polyAnD deposition.
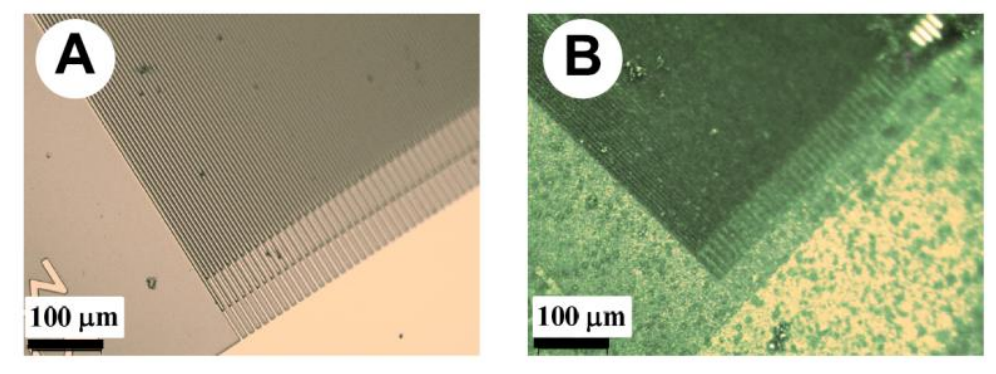

These figures are not provided in the submission, since the number of plots is already quite large. Corresponding comments are implemented in the text (p. 8).

4. Please, check spelling of Nyquist (on several places in the manuscript).

We are grateful to Reviewer for the comment, this mistyping was corrected.

5. How is the resistance (R) in Figures 4-6 related to the equivalent circuit and impedance spectra? Is the value of $\mathrm{R}$ obtained by fitting or is it the impedance value at a certain frequency? This should be explained.

The detailed answers to these questions are provided in the section 2.4 of the manuscript. The value of $\mathrm{R}$ was obtained by impedance spectra fitting. The resistance (R1) of polyAnD layer, obtained by spectra fitting to one of the equivalent circuits, is presented in Fig. 4-6.

6. On top of page 14 it is stated that "Re-oxidation processes provoke partial reduction of polyAnD chain and thereby affect the electrical conductivity of the polymer layer registered by impedance measurements." This statement is in agreement with the Graphical Abstract showing electron transfer from PQQ to the conducting polymer. However, this means that the conducting polymer is reduced and therefore it is surprising that the resistance decreases (Fig. 6). This is a very crucial point that seems to contradict the suggested reaction mechanism. Unless the polymer (polyAnD) would be n-doped, one would expect an INCREASE in resistance when polyAnD is reduced, i.e. transfered to a less oxidized (less pdoped, less conducting) state. This needs to be clarified, because it is important for the whole manuscript, including the graphical abstract.

We agree with the Reviewer, that the resistance of polyAnD should increase when electrons from enzyme active site are released into the polymer layer, because conductive polyaniline form became nonconductive leucoemeraldine. However, our studies showed opposite results. This interesting phenomenon is not fully understood yet.

As it is shown in Fig. 4 of the manuscript, the resistance of polymer goes down when the concentration of $\left[\mathrm{Fe}(\mathrm{CN})_{6}\right]^{4-}$ ions, as well as the solution redox-potential, increases. The same occurs during enzyme catalyzed redox-reactions with and without potassium 
ferricyanide. There are several possible explanations of this effect. 1) Pending group with dithiocarbamate moiety of polyAnD participates in redox-reactions. Pending group of polyAnD contains two nitrogen atoms, which can bound two protons and became positively charged. The protons as well as electrons can be released from enzyme active site during reoxidation processes. Thus, the environment close to the electrode surface became more acidic. Polyaniline conductivity is known to be induced by proton doping. This effect was applied in the case of "self-doped" polyanilines derivatives, when the charge compensation occurs at the expense of proton exchange, that occurs much more faster and do not limit the rate of the redox-process (A. Malinauskas, Self-doped polyanilines, J. Power Sources, 126 (2004) 214-220). The first example of the sensor based on conductivity of polyaniline derivative exploiting this phenomenon was recently presented (E.A. Andreyev, M.A. Komkova, V.N. Nikitina, N.V. Zaryanov, O.G. Voronin, E.E. Karyakina, A.K. Yatsimirsky, A.A. Karyakin, Reagentless Polyol Detection by Conductivity Increase in the Course of Self-Doping of Boronate-Substituted Polyaniline, Anal. Chem., 86 (2014) 11690-11695). 2) Resistance decrease can be explained by the following considerations. Properties of conducting polymers depend on where the redox-reactions with the environment occur: on the outer polymer/solution interface or within the polymer film bulk. If the reactions occur only on the polymer/solution interface without affecting the chemical composition of the bulk polymer, the environment oxygen can participate in the polymer surface oxidation processes and produce different reduced oxygen species, which can affect polymer conductivity (A. Malinauskas, R. Holze, An in situ spectroelectrochemical study of redox reactions at polyaniline-modified ITO electrodes, Electrochim. Acta, 43 (1998) 2563-2575).

Corresponding explanations were added to the text (pp. 14-15).

While preparing the revision of the manuscript we found that Figure 4 in the initial submission (Fig.5 in the revised version) had incorrect label (instead of $\left[\mathrm{Fe}(\mathrm{CN})_{6}\right]^{3-}$ $/\left[\mathrm{Fe}(\mathrm{CN})_{6}\right]^{4-}$ it has $\left[\mathrm{Fe}(\mathrm{CN})_{6}\right]^{4-} /\left[\mathrm{Fe}(\mathrm{CN})_{6}\right]^{3-}$ label). This was corrected in the revised manuscript.

\section{Reviewer \#3}

1) Correct the sentence "showed specific response in the presence of corresponding substrates with $1 \mu \mathrm{M}$ sensitivity" to"showed specific response in the presence of $1 \mu \mathrm{M}$ of the corresponding substrates".

The sentence was corrected

2) Analytical utility of EIS is not well documented. Additional references (especially review articles) should be added. In addition, excellent examples on the use of EIS to study changes of the biocatalyst's structure are notably missing.

We are grateful for this comment and corresponding references [2-8] proving analytical utility of EIS were added to the revised version of the manuscript. Please refer to p. 3 in the document. 
3) The meaning of the sentence "Oxidoreductases are the class of enzymes [14] and they catalyse selective oxidation or reduction of many organic compounds, which are of interest for various industry branches. Unfortunately, many oxidoreductases do not have DET [15] and only several electrode surface materials are suitable for DET [16]." is not clear. It needs editing.

The following reformulation was done to provide for more clarity: Oxidoreductases are the class of enzymes [20] that catalyze selective oxidation or reduction of many organic compounds and this class is of interest for various industrial applications. The redox-active moiety of most of the oxidoreductases is deeply buried within the enzyme globule [21]. Such spatial isolation protects enzyme active site from surrounding and provides effective kinetic barrier for DET. Thus, due to unique three-dimensional structure only certain types of oxidoreductases may participate in DET and only on specific electrode materials [22].

4) The sentence "2) the appropriate immobilization matrix compatible with enzyme on an electrode surface must be provided;" also needs editing.

The following correction was made: 2 ) the enzyme immobilization matrix must provide for enzyme adhesion, stabilization and orientation,

5) Correct "1.2-propandiol" to "1,2-propandiol" throughtout the manuscript.

This was corrected.

6) Correct the chemical formula of (NH4)3S2O8 to (NH4)2S2O8.

Corresponding correction was made.

7) The term "superficial adsorption" maybe replaced by the term "adsorption" or "physisorbed biomolecules".

The term "superficial adsorption" was replaced with physisorption.

8) Please check the upper limit of frequencies in the EIS experiments. Is that really so high 1 MHz? If yes, please explain why. Typically frequency values up to $100 \mathrm{kHz}$ are sufficient to describe the phenomena take place on the biomolecule-modified electrode/electrolyte interface.

This remark holds for ordinary EIS measurements between two bulk electrodes immersed in the solution. However in the case of EIS measurements with 3D-IDEA we have measured up to $1 \mathrm{MHz}$ in order to attain higher fitting precision from a broader range in Nyquist plot for the second semicircle. This is associated with the specific geometry of the sensor. Corresponding explanation was added to the text p. 9. 
9) Correct the term "Nyquist" throughout the text.

Corrections were made

10) Correct to "chi-square".

Corresponding correction was made.

11) Correct to "potentiostatic"

Correction was done.

12) Correct the title of 3.2 .

Reformulation: Influence of solution redox-potential on polyAnD resistance

13) The first sentence of paragraph 3.2 also needs editing.

Reformulation: Conducting polymers based on polyaniline and its derivatives are able to enhance the speed of various redox-processes as well as to participate in electrocatalytic oxidation of certain biologically important compounds, such as coenzymes and cytochromes.

14) The meaning of the sentence "his observation implies the relevance of using the same polymer material to register enzyme catalysed reactions in the conductive polymer." is not clear. Please explain or rephrase.

This sentence was rephrased as follows: "This phenomenon led us to assume that the same polymer material may be used to register the enzyme catalysed redox reactions."

15) Replace "inhibition" by "deactivation" (Page 12, line 59)

This was corrected.

16) Paragraph 3.5. The increase of the background signal after the modification of gold electrodes with polyAnD indicates an increase of the electrode surface rather than the presense of electroactive groups.

This sentence was reformulated: Modification of gold microelectrode by polyAnD with or without enzymes enhances the background current which indicates an increase of the electrode surface (curves (2) and (3)).

17) The quality of the data presented in Fig.7 is not sufficient to support DET between the enzyme and the electrode surface through the polyAnD layer. In addition, the respective text 
is also not clear for the reader. I would suggest authors to provide simple cyclic voltammetric experiment to document DET.

We agree with the referee that cyclic voltammetry (CV) experiments may confirm DET. We have performed CV measurements with polyAnD and enzymes to prove DET. However, our $\mathrm{CV}$ results contained significant noise since the electrode surface was too small to provide for clear signal (gold microelectrode area was only $1.65 \mathrm{~mm}^{2}$ ). Because of these technical difficulties we decided not to present the experimental graphs in the manuscript and chronoamperometry data were presented in the manuscript as alternative.

18) List of references should be checked. At least one reference is appearing twice; Biosensors Bioelectron., 24 (2008) 729-735 at Refs. 2 and 11.

We would like to thank the Reviewer for careful reading. This issue was corrected and other references were thoroughly checked. 


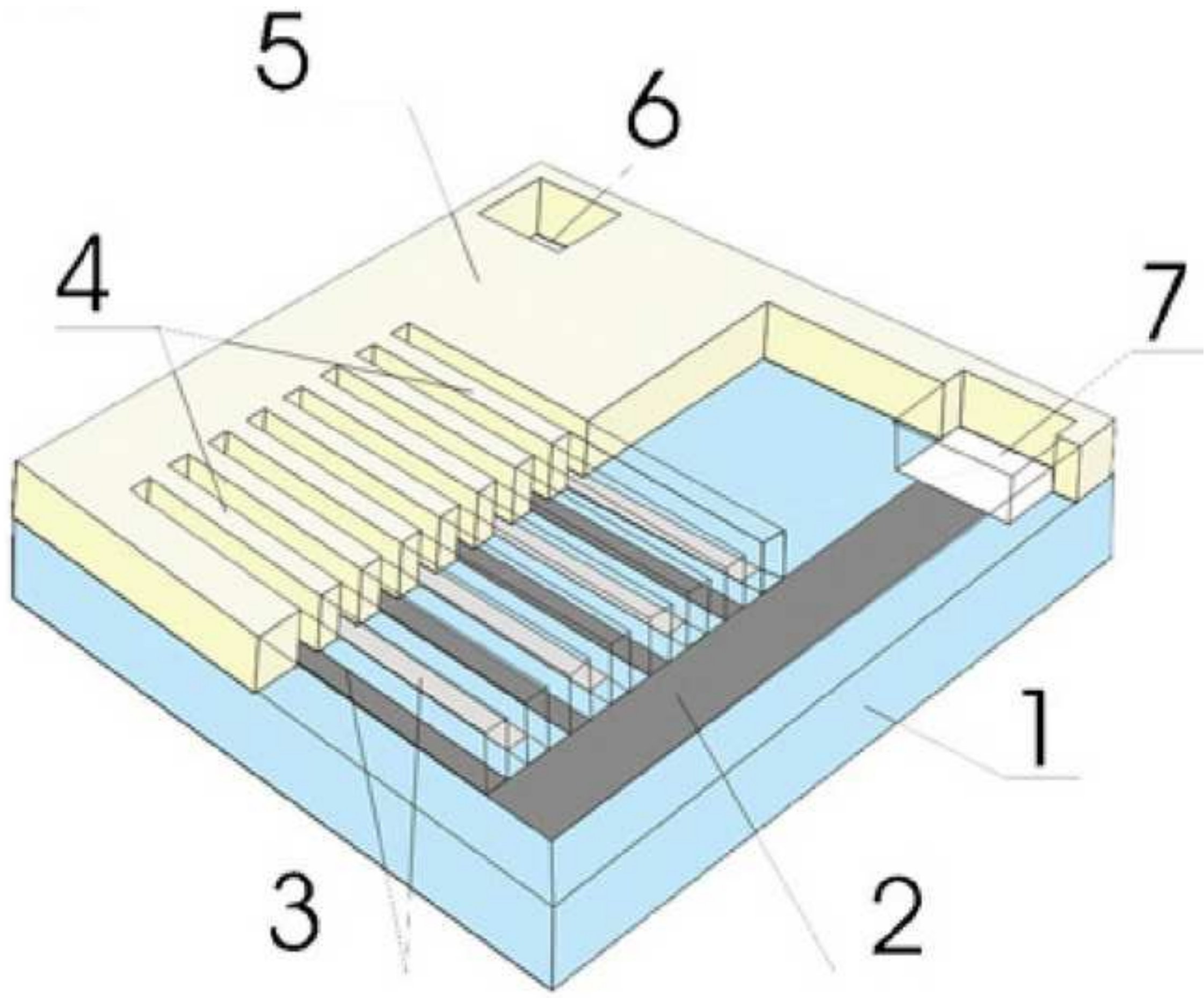


Click here to download high resolution image

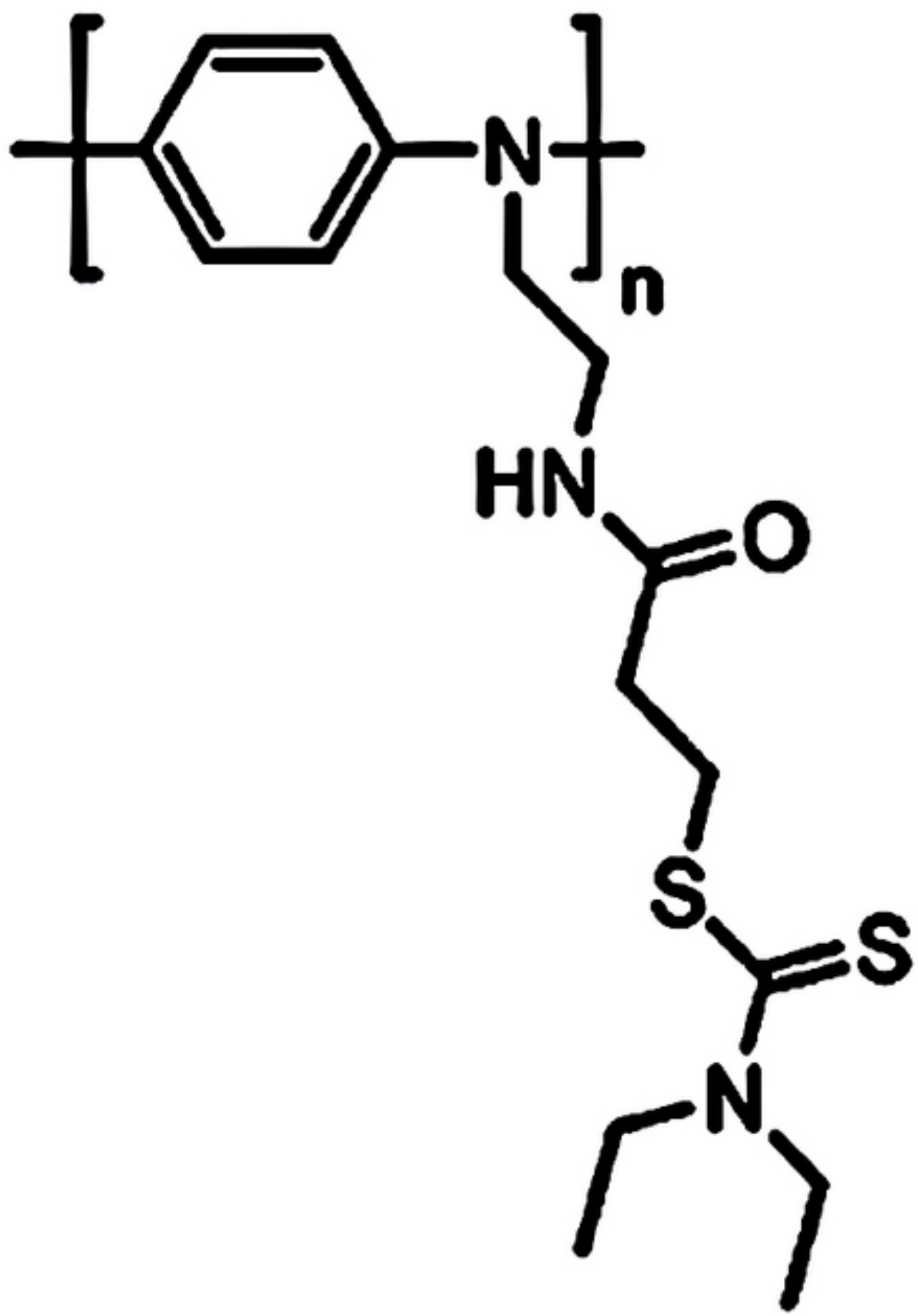


A

(1)

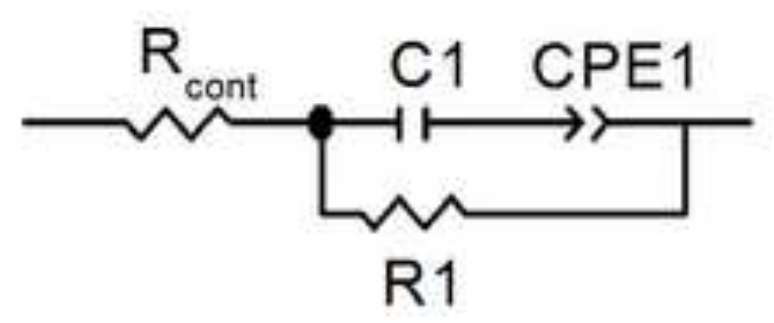

(2)

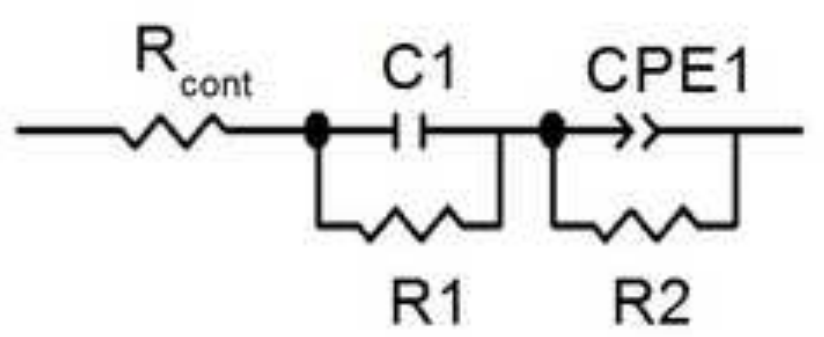

B

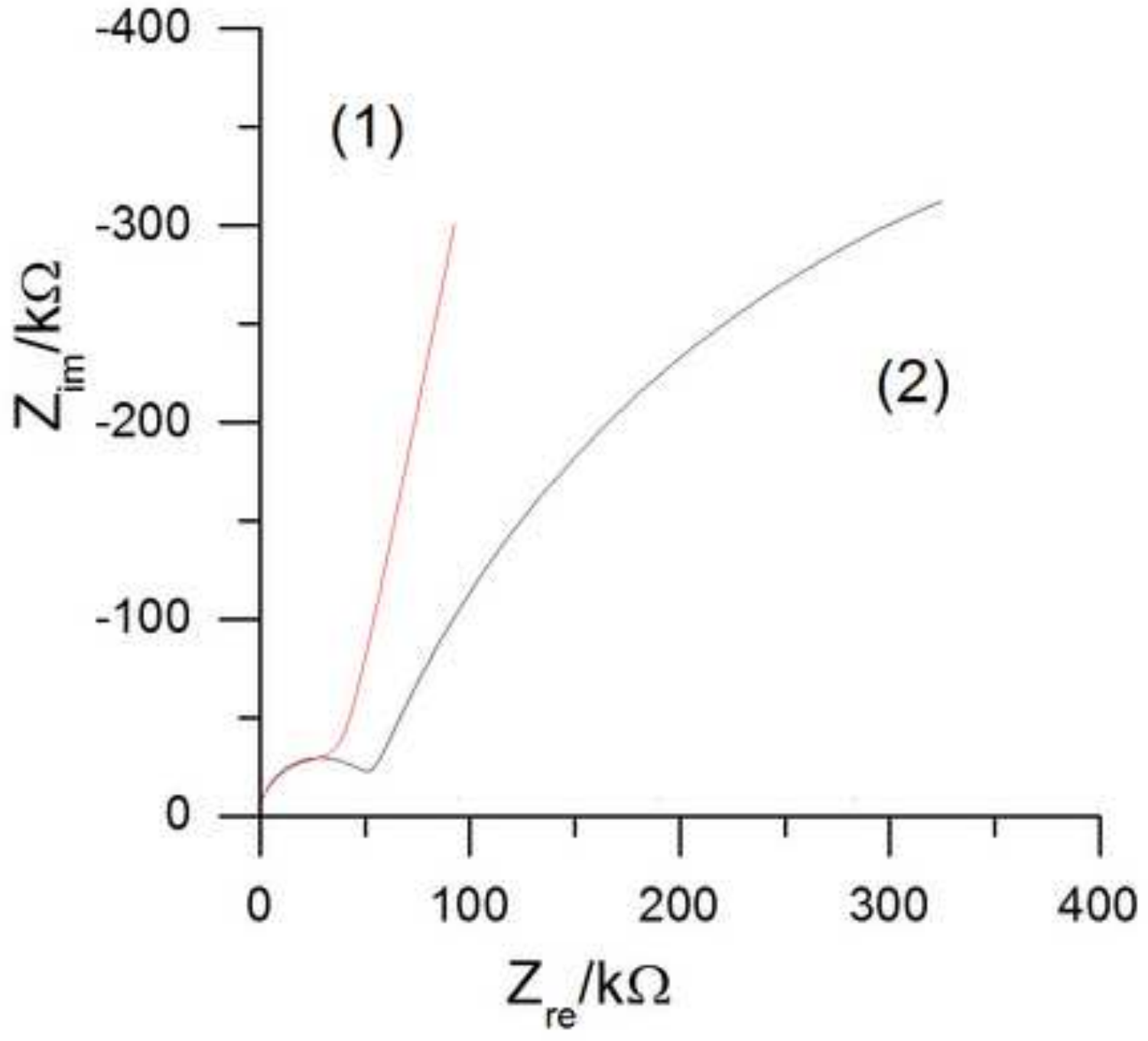


Figure(s)
Click here to download high resolution image

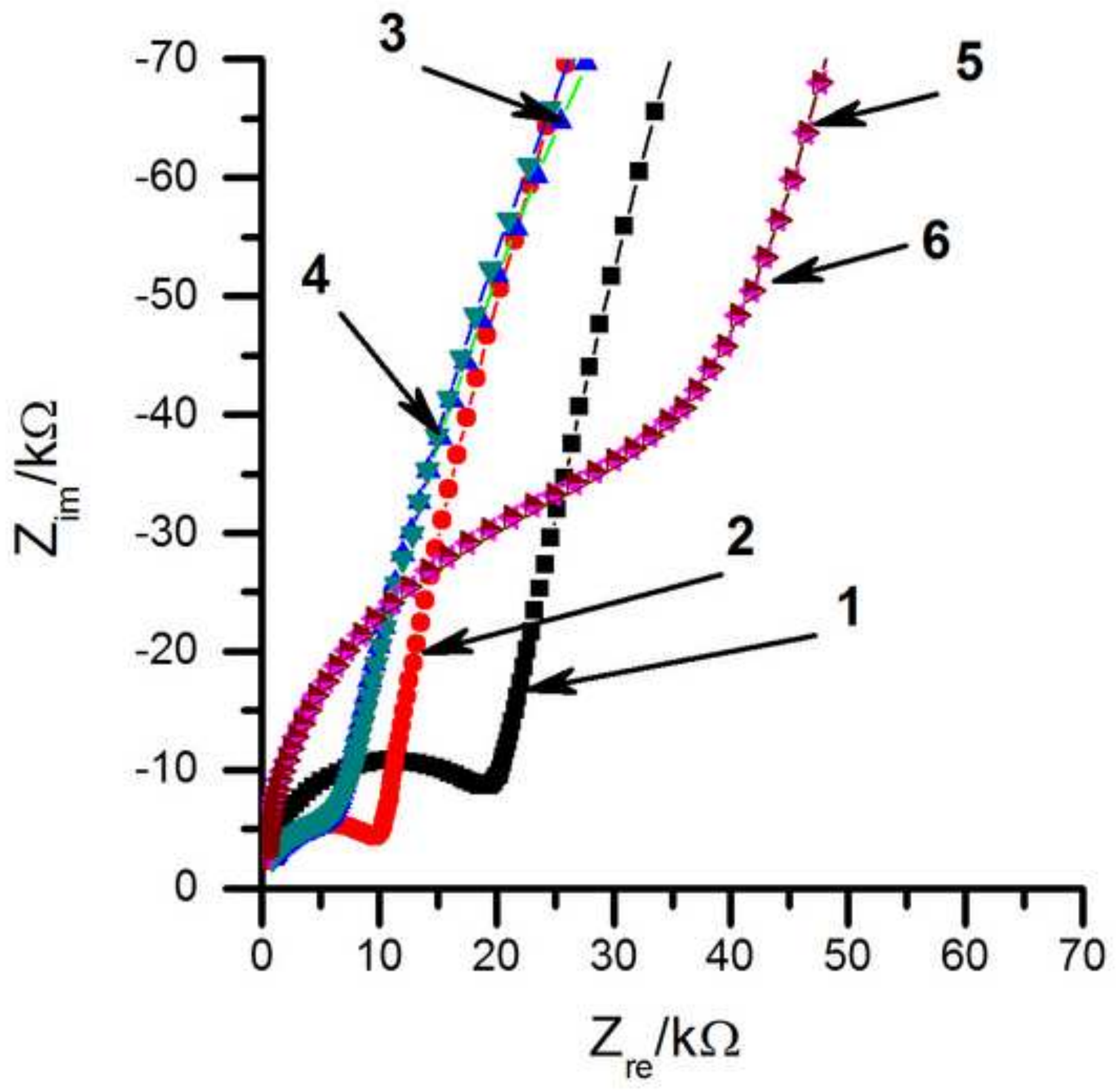




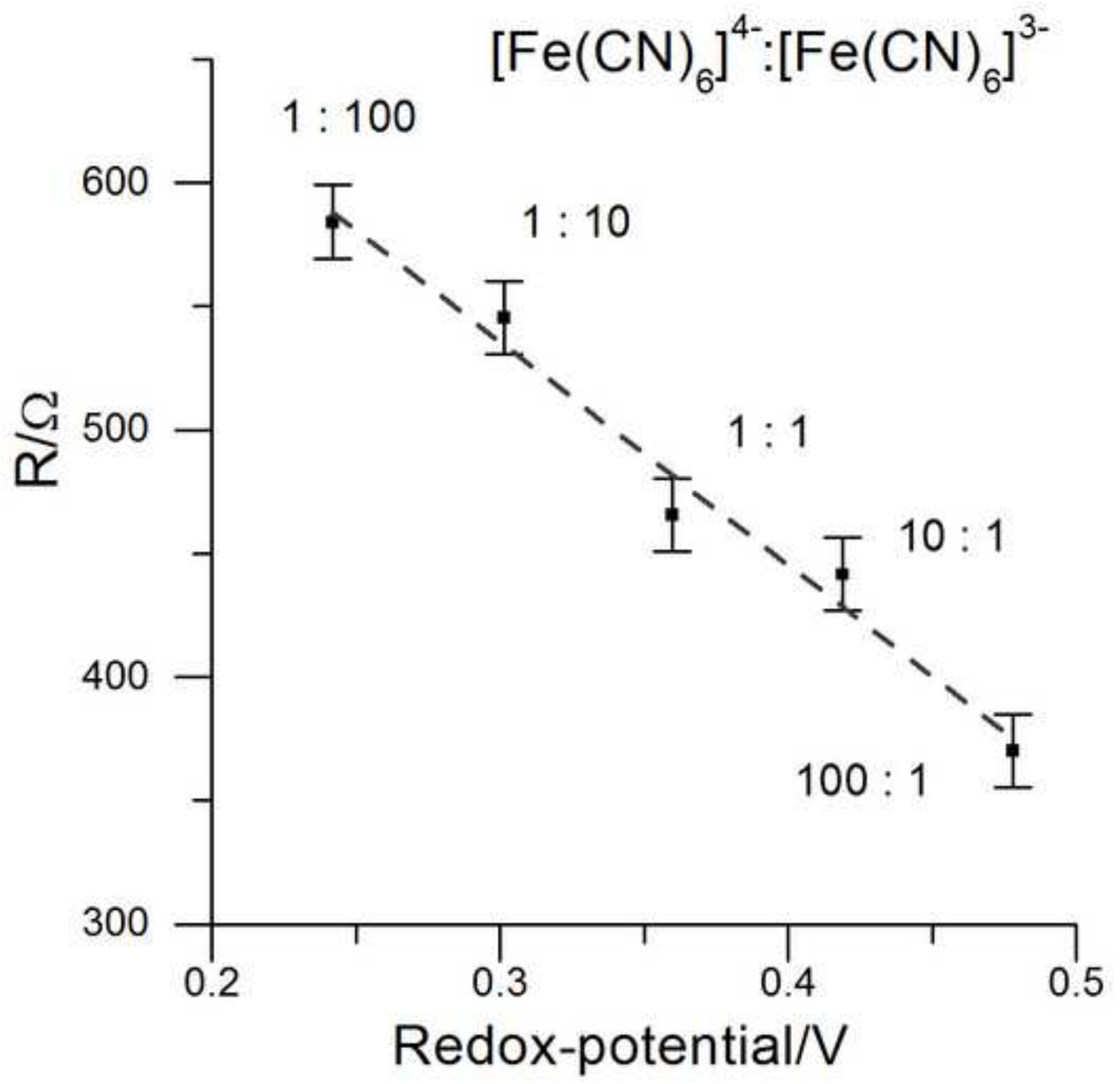


A polyAnD+sADH $\quad$ B polyAnD_sADH direct reoxidation on polymer

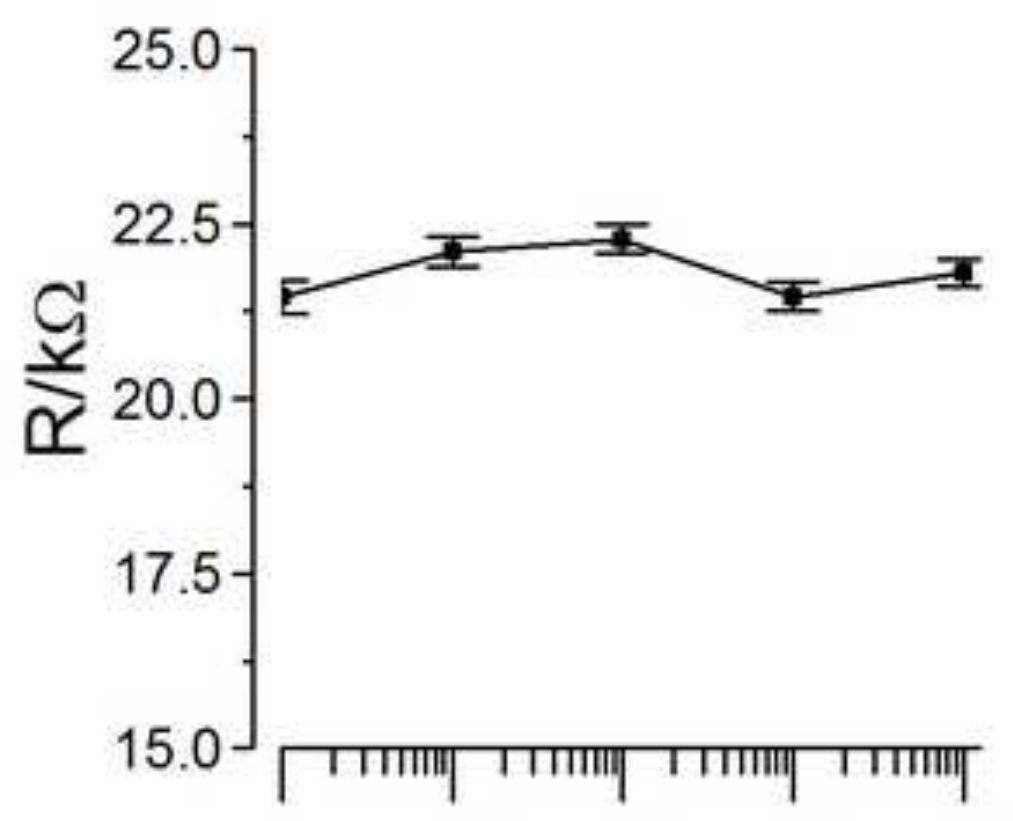

$$
\begin{array}{lllll}
0 & 10^{-6} & 10^{-5} & 10^{-4} & 10^{-3}
\end{array}
$$
$\log (\mathrm{c}(1,2$-propandiol $)) / \mathrm{mol} \mathrm{dm}^{-3} \log (\mathrm{c}(1,2$-propandiol $)) / \mathrm{mol} \mathrm{dm}^{-3}$

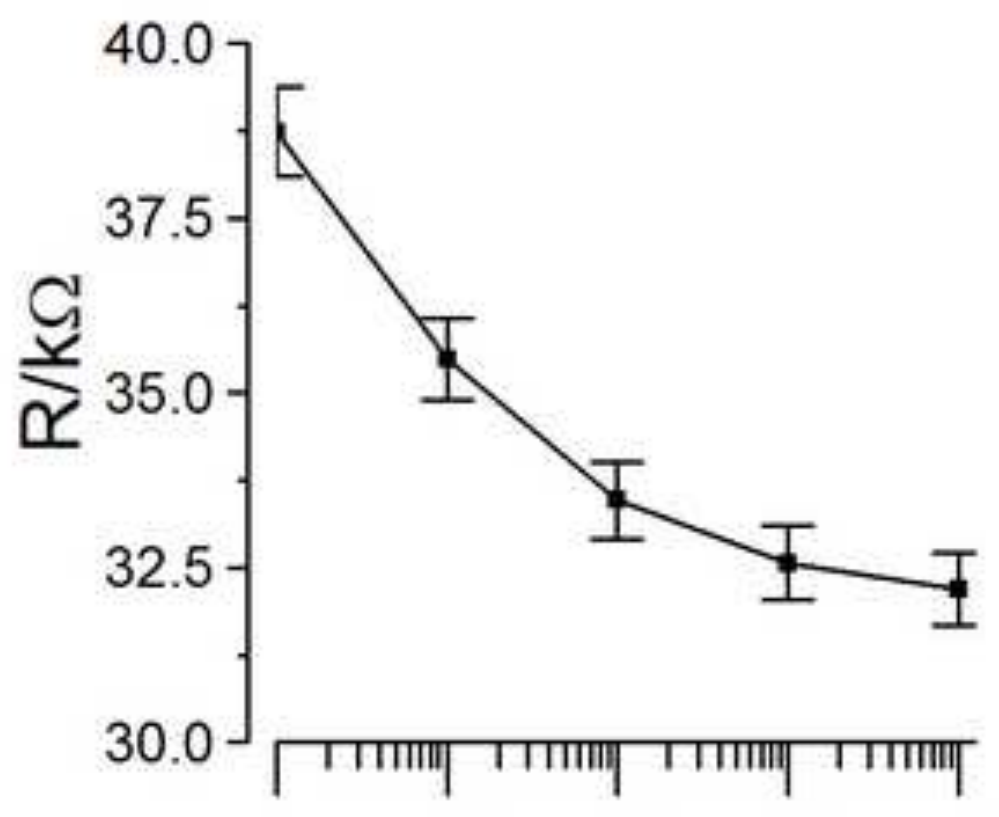

$\begin{array}{lllll}0 & 10^{-6} & 10^{-5} & 10^{-4} & 10^{-3}\end{array}$ 

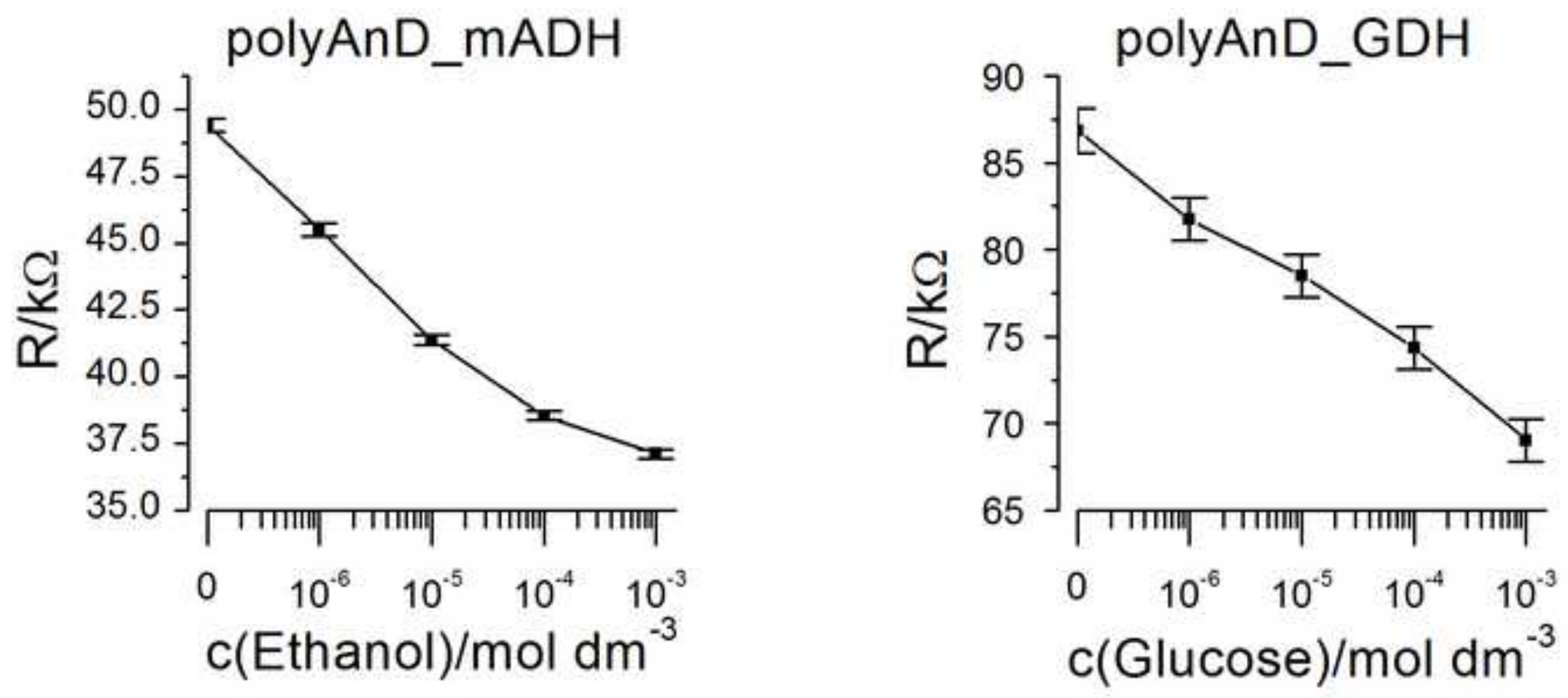
sADH

1,2-propandiol, $\mathrm{mol} \mathrm{dm}^{-3}$

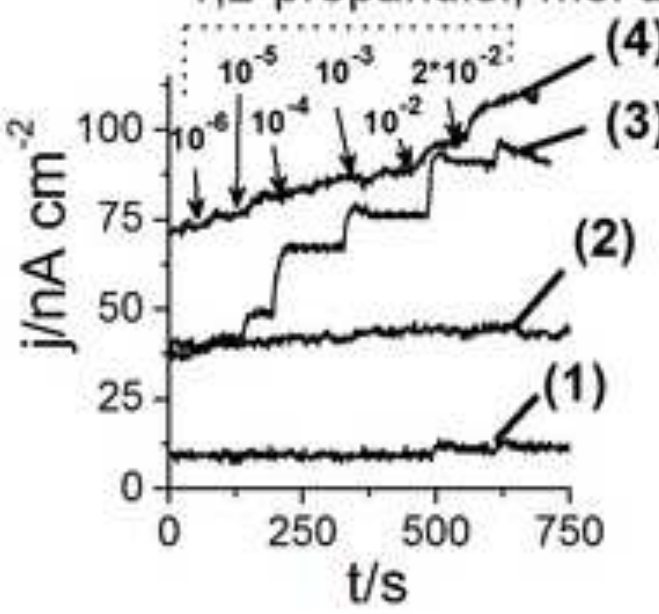

mADH ethanol, $\mathrm{mol} \mathrm{dm}^{-3}$

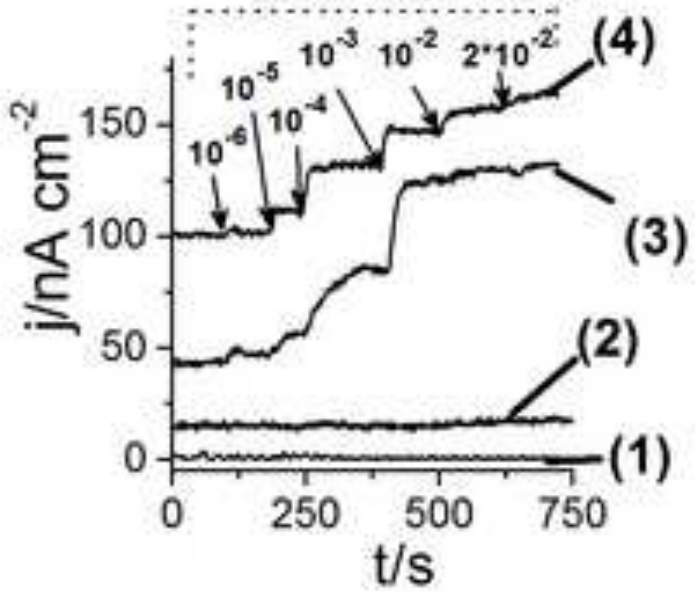

GDH

D-glucose, $\mathrm{mol} \mathrm{dm}^{-3}$

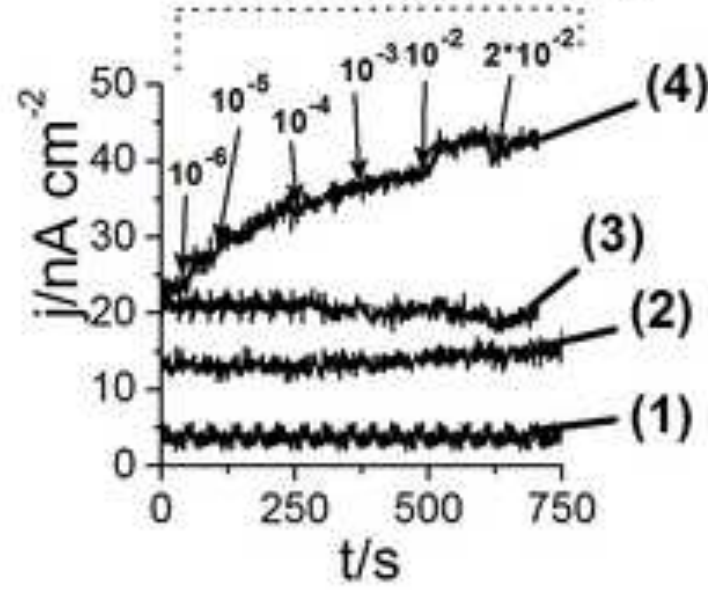




\title{
Development of label-free impedimetric platform based on new conductive polyaniline polymer and three-dimensional interdigitated electrode array for biosensor applications
}

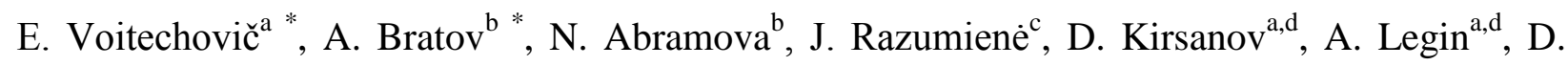

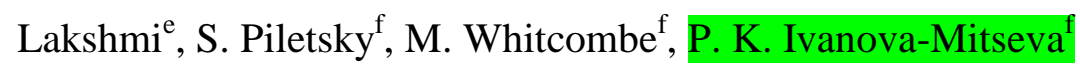

a Saint Petersburg State University, Department of Chemistry, Mendeleev Center, Universitetskaya Nab. 7-9, Saint Petersburg 199034, Russia

${ }^{\mathrm{b}}$ Institute of Microelectronics of Barcelona (IMB-CNM, CSIC), Campus UAB 08193 Bellaterra, Barcelona, Spain

${ }^{\mathrm{c}}$ Vilnius University, Institute of Biochemistry, Mokslininkų str. 12, LT-08662 Vilnius, Lithuania

${ }^{\mathrm{d}}$ Laboratory of artificial sensory systems, ITMO University, St. Petersburg, Russia.

\section{Sai Sarathy Limited, Milton Keynes, U.K.}

${ }^{\mathrm{f}}$ Research Group: Chemical Biology, Department of Chemistry, University of Leicester, Leicester, LE1 7RH, U.K.

* Corresponding authors:

\author{
Edita Voitechovič \\ e-mail: voitechovic.edita@gmail.com \\ Address: Saint Petersburg State University, Institute of Chemistry, \\ Mendeleev Center, Universitetskaya Nab. 7-9, Saint Petersburg 199034, \\ Russia \\ Tel.: +78123282835
}




\begin{abstract}
Novel label-free impedimetric platform based on a three-dimensional interdigitated electrode array (3D-IDEA) sensor and new conductive polymer as a transducer for oxidoreductases is introduced. This platform is cost-effective, simple to construct and miniaturize. Monomer of conductive polymer $\mathrm{N}$-(N',N'-diethyldithiocarbamoylethylamidoethyl)aniline (AnD) was deposited onto 3D-IDEA by chemical polymerisation. It was found that the polymer film resistance depends on the redox-potential of the solution. For the first time polyAnD was used as enzyme immobilisation matrix. Pyrroloquinolinequinone (PQQ) dependent alcohol and glucose dehydrogenases were immobilized on 3D-IDEA covered with polyAnD by two different methods. 3D-IDEA sensors with enzymes, which were immobilised by physisorption on polyAnD layer, showed specific response in the presence of $1 \mu \mathrm{M}$ of the corresponding substrates. Obtained results revealed that PQQ dependent dehydrogenases can re-oxidize on polyAnD via direct electron transfer (DET) from enzyme active site to the polymer surface. This process can be monitored by methods of electrochemical impedance spectroscopy (EIS) and chronoamperometry. Presented study shows that EIS method gives a useful tool for research of re-oxidation process and interaction of electroactive enzymes with conducting materials giving information required to construct and develop analytical devices.
\end{abstract}

Keywords: Interdigitated electrode array, DET, PQQ dependent enzyme, polyaniline, biosensor 


\section{Introduction}

Nowadays there are numerous fields such as medicine, microbiology, food and environmental protection where ultrasensitive and fast sensors for determination of various analytes are required. The sensors based on biocatalysts and electrochemical detection gained wide attention from researchers due to their unique sensitivity, cost-effectiveness, short-time analysis, capability of measurements in dispersed and nontransparent solutions. Moreover these devices are easy to miniaturize.

There are different electrochemical methods, which are employed to construct biosensors: amperometry, voltammetry, potentiometry, coulometry, conductometry and electrochemical impedance spectroscopy (EIS) [1]. EIS is a powerful analytical tool that is employed successfully in chemical and biochemical analysis [2-5], as well as to study biocatalysis on the surface of electrodes [6-8]. EIS is widely applied in physical and biological sciences especially in the field of biosensor research [9]. EIS can provide information on the changes of biocatalyst structure or electrode matrix structure $[10,11]$. Moreover, in comparison with other electrochemical methods, EIS setup does not require a reference electrode and analysis can be performed without high potential treatment of the electrode surface, that can destroy thin and sensitive bioactive layer of the sensor [12]. Impedimetric biosensors are employed for quantitative and qualitative immunoanalysis [10], determination of nucleoacids, their mutations [13] and different redox-active compounds [14], e.g. $\mathrm{H}_{2} \mathrm{O}_{2}$. However, the possibility of impedance measurements often requires the presence of redox-active species in test solution, e.g. usually ferricyanide/ferrocyanide couple is used. In this case Faradaic charge transfer resistance is measured, which may be affected by interactions of a target biomolecule with a probefunctionalized sensor surface [15]. To avoid addition of redox-agents and to be able to perform the measurements immediately on the area close to the electrode surface the capacitive 
biosensors based on interdigitated electrode arrays (IDEA) were introduced [16]. In this case biochemical reactions at the sensor surface are registered as capacitance changes in non-Faradaic measurements. Planar microband electrodes of IDEA, between which the impedance is measured, are very closely situated, so that in this case changes in electrical properties of the interdigital space may affect the sensor impedance [15]. Several years ago the concept of a threedimensional interdigitated electrode arrays (3D-IDEA) with electrode fingers separated by an insulating barrier was proposed $[9,17]$. The specific design of this sensor structure allows for enhancement of its sensitivity for biochemical reactions taking place at the sensor surface [18]. The principles and applications of 3D-IDEA sensors were recently discussed in [15].

Another opportunity to avoid the addition of redox-compounds or special labels for analytes into the test solution is an application of electrochemical systems based on redox-active enzymes oxidoreductases, since some of them can possess direct electron transfer (DET) from an enzyme active site to the electrode surface. The effective direct re-oxidation of enzyme onto electrode surface ensures the highest selectivity of analysis, independence of oxygen concentration in the media, analysis at lower potential and simplifies the sensor construction [19]. Due to this, DET became a phenomenon, which is extensively investigated during last several decades. Oxidoreductases are the class of enzymes [20] that catalyze selective oxidation or reduction of many organic compounds and this class is of interest for various industrial applications. The redox-active moiety of most of the oxidoreductases is deeply buried within the enzyme globule [21]. Such spatial isolation protects enzyme active site from surrounding and provides effective kinetic barrier for DET. Thus, due to unique three-dimensional structure only certain types of oxidoreductases may participate in DET and only on specific electrode materials [22].

Broad applicability of 3D-IDEA sensors to study interactions of biomolecules [18] can be useful to apply this sensor type for investigation of oxidoreductases. A synergism of 3D-IDEA and unique selectivity of oxidoreductases can be promising to design label-free ultrasensitive new 
impedimetric biosensor, based on determination of the changes only in the electrical properties of immobilised enzyme layer and enzyme immobilisation matrix. In order to construct such biosensor platform several requirements must be fulfilled: 1) the enzyme must possess DET; 2) the enzyme immobilization matrix must provide for enzyme adhesion, stabilization and orientation; 3) the immobilization matrix must have reasonable conductivity [23-26].

To address the first issue one can consider pyroloquinolinquinone (PQQ) dependent oxidoreductases which represent a unique group of enzymes that can act as electrocatalysts, facilitating the electron transfer between different conductive electrode materials and their substrate molecule with no mediator involved in the process [27-29]. It is important to note that PQQ dependent enzymes do not react with molecular oxygen and, consequently, they are attractive for construction of the third generation biosensors [19] based on the DET between enzyme and electrodes. Previous investigations showed that PQQ dependent enzymes exchange electrons with gold, silver, pyrolytic graphite, several organic polymers, glassy carbon and carbon paste electrodes [30-35]. In addition, the efficiency of the DET is highly dependent on the intrinsic properties of the electrode material.

In order to address the second and the third issues one can apply various conducting polymers which are very attractive materials as their properties may be tuned chemically in a desired way to assist with electron transfer [36, 37].

Conducting polymers, especially polyanilines, have a great potential in electronics and optics $[38,39]$ and especially in the field of chemical sensors and biosensors [3, 37, 40, 41]. Due to their peculiar electrochemical and optical properties these materials can be used as components of different transducers in potentiometric, amperometric and impedimetric/conductimetric sensors [3]. They are frequently employed as sensitive elements of "chemiresistors" for gas sensing [42]. These polymers were found to change their electronic conductivity in response to changes in $\mathrm{pH}$ or redox-potential of the solution in contact with the polymer $[43,44]$ and were 
suggested to be applied as chemical or redox-sensors [45]. Biosensors with conducting polymers are most commonly used in amperometric detection [3], though conductimetric sensors with different enzymes have also been reported [46-48]. Recently new $N$-substituted aniline derivatives with interesting features were reported in the literature [36, 49]. These monomers contain two essential parts: aniline and methacrylamide or dithiocarbamate. Recently one of such monomers $N-\left(N^{\prime}, N^{\prime}\right.$-diethyl dithiocarbamoyl ethyl amido ethyl)aniline (AnD) [36] is introduced. The aniline part of this substance can be polymerized in both chemical and electrochemical way and conductivity of the resulting polymer is similar to that of aniline. An attractive feature of polyAnD molecule is that each monomer unit has a dithiocarbamate ester moiety, and it can be used for further surface modification. UV grafting can be applied for grafting of other polymers over polyAnD via iniferter activation. Moreover, it was shown, that polyAnD can be used as molecular imprinted polymer for amperometric determination of certain organic compounds [50]. These features seem useful and are more advantageous in comparison with other conducting polymers for construction and directional modification of electrode matrix for design of bio-compatible enzyme immobilisation matrix with high surface area.

In this study we introduce a novel label-free impedimetric platform based on 3D-IDEA sensor and new conductive polyaniline polymer polyAnD as a transducer for oxidoreductases. The three different PQQ dependent dehydrogenases were applied to test suitability of the proposed impedimetric platform for studying of electron transfer processes between enzymes and immobilization matrix and for biosensing purposes as well.

\section{Experimental}

\subsection{Enzymes and chemicals}

Membrane bound PQQ dependent alcohol dehydrogenase (mADH) from Gluconobacter sp. 33, E.C. 1.1.5.5, was isolated and purified by the method reported in [51]. The activity of the 
enzyme solution in $5 \mathrm{mM}$ Tris buffer ( $\mathrm{pH} 7.5$ ) with $1 \mathrm{mM} \mathrm{CaCl}_{2}, 0.02 \%$ Triton-X-100 and $0.5 \%$ sucrose was $200 \mathrm{U} / \mathrm{ml}$. Ethanol was used as default substrate for the mADH.

Soluble PQQ dependent alcohol dehydrogenase (sADH) from Pseudomonas putida HK5, E.C. 1.1.9.1, was isolated and purified by the method reported in [52]. The activity of the enzyme solution in $5 \mathrm{mM}$ Tris buffer $(\mathrm{pH} 8.5)$ with $5 \mathrm{mM} \mathrm{CaCl}_{2}$ was $130 \mathrm{U} / \mathrm{ml}$. 1,2-propandiol was used as the default substrate for the sADH.

Soluble PQQ dependent glucose dehydrogenase (GDH) from Acinetobacter calcoaceticus, E.C. 1.1.5.2, was isolated and purified by the method reported in [53]. The activity of the enzyme solution in $5 \mathrm{mM}$ Tris buffer (pH 8.0) with $1 \mathrm{mM} \mathrm{CaCl}_{2}$ was $1800 \mathrm{U} / \mathrm{ml}$. D-(+)-glucose was used as a default substrate for the GDH.

All enzymes were purified at the Department of Molecular microbiology and biotechnology (Vilnius University, Institute of Biochemistry) (Lithuania) and were kindly provided by Dr. R. Meškys.

Monomer of conductive polyaniline polymer N-(N', N'-diethyl dithiocarbamoyl ethyl amido ethyl)aniline (AnD) was synthesized according to the method reported earlier [36].

Sodium acetate, acetic acid, $\mathrm{CaCl}_{2}$ and 1,2-propandiol were obtained from J.T. Baker (Holland, the Nederland's). Ethanol, $\mathrm{KCl}$ and D-(+)-glucose were purchased from Riedel-de Haen (Denmark). $\mathrm{K}_{3}\left[\mathrm{Fe}(\mathrm{CN})_{6}\right], \mathrm{K}_{4}\left[\mathrm{Fe}(\mathrm{CN})_{6}\right], \mathrm{HCl}$, acetonitrile, $\mathrm{N}_{2},\left(\mathrm{NH}_{4}\right)_{2} \mathrm{~S}_{2} \mathrm{O}_{8}$ (APS) were purchased from Sigma Aldrich (Germany).

Three dimensional IDEA electrodes were fabricated at the IMB-CNM, CSIC (Spain) as described in [9]. The scheme of 3D-IDEA sensor is presented in Fig. 1.

Gold microelectrodes (working area $1.64 \mathrm{~mm}^{2}$ ) were fabricated at the same facility by deposition of titanium $(10 \mathrm{~nm})$ and gold $(100 \mathrm{~nm})$ onto a silicon wafer covered with $1 \mu \mathrm{m}$ thick silicon oxide layer. Electrodes were patterned using conventional lift-off technique. 
FIG1 here

\subsection{AnD polymerisation}

Oxidative polymerization was performed following the method reported in [36] using APS under the following conditions: $0.018 \mathrm{M}$ APS, $0.025 \mathrm{M} \mathrm{AnD}, 0.225 \mathrm{M} \mathrm{HCl}, 25 \%$ acetonitrile in water. The reaction mixture was prepared by mixing $250 \mu \mathrm{l}$ of AnD $(0.1 \mathrm{M}$ in acetonitrile $)$ with $207 \mu \mathrm{l}$ of an aqueous solution of APS $(0.0915 \mathrm{M}), 230 \mu \mathrm{l}$ of $\mathrm{HCl}(1 \mathrm{M})$, and $680 \mu \mathrm{l}$ of water. The solution was transferred to the Eppendorf tube where a sensor was immersed and fixed vertically. Polymerisation was carried out during $1.5 \mathrm{~h}$ at room temperature in the dark resulting in the deposition of a thin, green layer of functionalized polyAnD coating over the electrode surface. This process was controlled with optical microscopy to ensure the uniform deposition of the polymer. PolyAnD structure is presented in Fig. 2. PolyAnD-coated transducers were washed in three cycles with de-ionised (DI) water and dried in a nitrogen flow.

FIG2 here

\subsection{Immobilisation of enzymes}

Two methods were employed for enzyme immobilisation: entrapment in polyAnD and physisorption. Immobilisation of sADH enzyme by entrapment was performed as follows. The reaction mixture was prepared by mixing $250 \mu \mathrm{l}$ of $\mathrm{AnD}(0.1 \mathrm{M}$ in acetonitrile) with $207 \mu 1$ of aqueous solution of APS $(0.0915 \mathrm{M}), 230 \mu \mathrm{l}$ of $\mathrm{HCl}(1 \mathrm{M})$, and $690 \mu \mathrm{l}$ of sADH solution $(0.9$ $\mathrm{mM})$. The solution was transferred to the Eppendorf tube where the sensor was immersed and 
fixed vertically. Polymerisation was carried out during $1.5 \mathrm{~h}$ at room temperature in the dark. Enzyme and polymer modified electrodes were rinsed several times with DI water and dried in a nitrogen flow.

Physisorption of enzymes was done as follows: $2 \mu$ l of enzyme solution were dropped onto premodified with polyAnD electrode surface and kept at $+4{ }^{0} \mathrm{C}$ for $1 \mathrm{~h}$. Enzyme modified electrodes were carefully washed with DI water and dried in a $\mathrm{N}_{2}$ flow.

\subsection{Impedance measurements}

Characterisation of 3D-IDEA sensors was performed by impedance measurements in a $100 \mathrm{~Hz}-$ $1000 \mathrm{kHz}$ frequency range with a $25 \mathrm{mV}$ (amplitude) voltage excitation using PARSTAT 2263 Advanced Electrochemical System (Princeton Applied Research, USA) in $0.01 \mathrm{mM} \mathrm{CaCl}{ }_{2}$ water solution. Such frequency range for measurements was chosen in order to attain higher fitting precision from a broader range in Nyquist plot. This is associated with the specific geometry of the sensor. The enzyme substrates solutions, containing $100 \mathrm{mM}$ of ethanol, $100 \mathrm{mM} \mathrm{1,2-}$ propandiol or $100 \mathrm{mM}$ of D-glucose were prepared using $0.01 \mathrm{mM} \mathrm{CaCl}_{2}$ as a background. ZPlot/Z-View software package (Scribner Associates, Southern Pines, NC, USA) was employed for data treatment and an equivalent circuit fitting. Fig. 3. shows two equivalent circuit models of 3D-IDEA sensor. These models were applied for fitting of impedance spectra.

\section{FIG3 here}

The first equivalent circuit presented in Fig. 3 A (1) was used for spectra fitting when only one semicircle appears in a spectrum at high frequencies and the low frequency part on the Nyquist 
plot is linear. In water solutions where the studied systems showed spectra with two semicircles as presented in Fig. 3 B (2), the second equivalent circuit was used to fit them.

The parameter $\mathrm{R}_{\text {cont }}$ is the resistance of the electrodes contacts. Parallel combination of the $\mathrm{C} 1$ $\mathrm{R} 1$ represents the resistance of the polyaniline layer and the geometrical capacitance of the IDEA sensor and CPE1 and R2 present the capacitance and resistance at the interface between the polymer and the solution.

The quality of fit can be assessed with the chi-square parameter which is the sum of squares of the ratio of the standard deviation between the original data and the calculated spectrum. For all spectra measured in this work the chi-square parameter was typically smaller than 0.0025 .

\subsection{Amperometric measurements}

The electrochemical system PARSTAT 2273 (Princeton Applied Research, USA) was employed for amperometric experiments. The system has a conventional three-electrode cell with saturated $\mathrm{Ag} / \mathrm{AgCl}$ reference electrode, platinum plate auxiliary electrode and working gold microelectrode.

Before the experiments gold microelectrodes were rinsed with DI water and sonicated in DI water for $10 \mathrm{~min}$. Then they were electrochemically cleaned by potential scanning from $-0.2 \mathrm{~V}$ to $1.7 \mathrm{~V}$ (vs. $\mathrm{Ag} / \mathrm{AgCl}$ ) $10-20$ times at $200 \mathrm{mV} / \mathrm{s}$ scan rate in $0.5 \mathrm{M} \mathrm{H}_{2} \mathrm{SO}_{4}$ water solution until reproducible gold oxide stripping peaks were obtained.

Chronoamperometric measurements were employed to study the response of the biosensor to substrate addition. The conditions were as follows: potentiostatic mode at $+400 \mathrm{mV}$ (vs. $\mathrm{Ag} / \mathrm{AgCl})$ in a stirred $100 \mathrm{mM}$ acetate buffer solution, $\mathrm{pH} 6.0,10 \mathrm{mM} \mathrm{CaCl}{ }_{2}$ and $10 \mathrm{mM} \mathrm{KCl}$. The enzyme substrates were used as acetate buffer solutions, $\mathrm{pH} 6.0$, containing $100 \mathrm{mM}$ of ethanol, $100 \mathrm{mM}$ 1,2-propandiol or $100 \mathrm{mM}$ of D-glucose. 


\section{Results and discussion}

\subsection{D-IDEA sensors modifications}

3D-IDEA sensors were modified with polyAnD polymer by chemical polymerisation. The impedance spectra before and after modification were measured in solutions of $\mathrm{CaCl}_{2}$ with different conductance and the results are presented in Fig. 4. As expected, spectra of the initial sensor before modification depend on the solution conductivity (curve 1 and 2). After deposition of the polymer film the sensor shows rather small interelectrode resistivity that is only slightly affected by changes in the solution conductivity (curve 3 and 4). This is due to the presence of a highly conductive film that shunts the electrodes and prevents penetration of the electric field into the solution. Adsorption of enzymes on the polyAnD provokes significant impedance changes (curve 5), which didn't decrease during months after immobilisation. The resistance of the film composed of polyAnD and enzyme becomes several times higher. This means that there is an interaction between PQQ dependent enzymes and the conductive polymer that affects its electrical properties. However, as in the previous case, the sensor impedance was not affected by the solution conductivity (curves 5 and 6) and there were no differences between impedance spectra obtained in solutions with $4.62 \mu \mathrm{S} / \mathrm{cm}$ and $16.8 \mu \mathrm{S} / \mathrm{cm}$ conductivity.

\section{FIG4 here}

\subsection{Influence of solution redox-potential on polyAnD resistance}

Conducting polymers based on polyaniline and its derivatives are able to enhance the speed of various redox-processes as well as to participate in electrocatalytic oxidation of certain biologically important compounds, such as coenzymes and cytochromes $[54,55]$. 
The enzymes studied in this work have quinone cofactor and one or more heme $\mathrm{c}$ in their active sites. In this case, it is possible, that polyAnD could also provoke re-oxidation of enzymes active sites during substrate oxidation. It is also known that polyaniline based polymers are sensitive to solution redox-potential changes. In this case electric properties of polyAnD should change in the presence of soluble electron acceptor in solution, when concentration of oxidised and reduced forms changes during the enzyme catalysed substrate oxidation.

Firstly, the sensitivity of polyAnD to redox-potential was tested. The impedance spectra of polymer modified sensor were recorded in solutions with different ratio of $\left[\mathrm{Fe}(\mathrm{CN})_{6}\right]^{3-}$ $/\left[\mathrm{Fe}(\mathrm{CN})_{6}\right]^{4-}$. These ions are chosen due to ferricyanide is known as good electron acceptor of heme containing enzymes, as $\mathrm{sADH}$ and $\mathrm{mADH}$ are. The resistance (R1) of the sensor was determined by fitting of impedance spectra by equivalent circuit model Fig. 2 A (1). The redoxpotentials of solutions were calculated using Nernst equation:

$$
E=E_{0}+\frac{R T}{F n} \ln \frac{\left[\left[\mathrm{Fe}(\mathrm{CN})_{6}\right]^{3-}\right]}{\left[\left[\mathrm{Fe}(\mathrm{CN})_{6}\right]^{4-}\right]},
$$

where $\mathrm{E}_{0}=0.36 \mathrm{~V}$ is the standard redox-potential of the $\left[\mathrm{Fe}(\mathrm{CN})_{6}\right]^{3-} /\left[\mathrm{Fe}(\mathrm{CN})_{6}\right]^{4-}$ pair in water solution. Data are presented in the Fig. 5. The polymer film resistance goes down linearly as the redox-potential of the solution becomes more positive. This phenomenon led us to assume that the same polymer material may be used to register the enzyme catalysed redox reactions.

\section{FIG5 here}

\subsection{Response of the sensor with soluble alcohol dehydrogenase (sADH)}

The bioelechtrochemical systems with sADH on the polyAnD modified 3D-IDEA sensors were constructed using enzyme immobilisation by entrapment (polyAnD+sADH) and by 
physisorption (polyAnD_sADH). The response of both systems to addition of enzyme substrate was recorded in the presence and absence of water soluble electron acceptor $\mathrm{K}_{3}\left[\mathrm{Fe}(\mathrm{CN})_{6}\right]$ in a small volume $(500 \mu 1)$ of reaction solution.

The polyAnD_sADH system showed specific response to addition of 1,2-propandiol in the presence of $\mathrm{K}_{3}\left[\mathrm{Fe}(\mathrm{CN})_{6}\right]$ resulting in the resistance decrease, similar to previous experiments with different ratio of $\left[\mathrm{Fe}(\mathrm{CN})_{6}\right]^{3-} /\left[\mathrm{Fe}(\mathrm{CN})_{6}\right]^{4-}$. These results show that sADH is able to change significantly $\mathrm{K}_{3}\left[\mathrm{Fe}(\mathrm{CN})_{6}\right]$ concentration during biocatalysis. However, the (polyAnD+sADH) system with entrapped sADH showed no specific response to the presence of 1,2-propandiol, that can indicate deactivation of sADH during polymerisation process.

The response of sensors with adsorbed and entrapped sADH and 3D-IDEA sensor covered with polyAnD to addition of 1,2-propandiol was measured without $\mathrm{K}_{3}\left[\mathrm{Fe}(\mathrm{CN})_{6}\right]$ expecting that polyAnD could provoke re-oxidation of sADH active site. These results are shown in Fig. 6.

\section{FIG6 here}

The sensor with adsorbed sADH showed specific response to addition of the enzyme substrate (Fig. 6. B), while the sensor with entrapped enzyme showed no response (Fig. 6. A) in experiments with $\mathrm{K}_{3}\left[\mathrm{Fe}(\mathrm{CN})_{6}\right]$. From this we can conclude that the enzyme activity is affected by the polymerisation process. It was shown in ref. [56] that sADH exhibits $35-5 \%$ of its initial activity after $1 \mathrm{~h}$ storage in $25 \%$ acetonitrile water solution. In our case, the presence of organic solvent is accompanied by low solution $\mathrm{pH}$ and release of oxygen during chemical reactions which provoke an irreversible denaturation of sADH globule. This method of enzyme immobilisation was not used further in experiments. 


\subsection{Response of the sensors with membrane bound alcohol dehydrogenase (mADH) and soluble glucose dehydrogenase (GDH)}

Since enzyme immobilisation by entrapment in polyAnD resulted in a total loss of enzyme activity, PQQ dependent membrane bound alcohol dehydrogenase and soluble glucose dehydrogenase were immobilised onto polyAnD modified 3D-IDEA sensors by physisorption. As in the case of sADH, we recorded impedance spectra of obtained sensors in the presence of different concentration of enzymes substrates. The results of these experiments are presented in Fig. 7. Sensors with mADH and GDH show decrease in determined resistance (R1) upon addition of enzymes substrates. This suggests that all studied enzymes in this work can undergo direct re-oxidation on polyAnD.

\section{FIG7 here}

Enzymes re-oxidation means electron flow to the polymer from reduced enzyme active site. Reduction processes of the conducting polymer chains usually result in conductivity decrease. However, obtained results with $\left[\mathrm{Fe}(\mathrm{CN})_{6}\right]^{3-} /\left[\mathrm{Fe}(\mathrm{CN})_{6}\right]^{4-}$ (section 3.2) and all studied enzymes showed opposite behaviour. This interesting phenomenon is not fully understood yet. There are several possible explanations for this effect. First one can be attributed to pending group with dithiocarbamate moiety of polyAnD, which can participate in redox-reactions. Pending group of polyAnD contains two nitrogen atoms (Fig. 2), which can bound two protons and became positively charged. The protons as well as electrons can be released from enzyme active site during PQQ re-oxidation processes $[57,58]$. Thus, the environment close to the electrode surface should become more acidic. Polyaniline conductivity is known to be induced by proton doping. This effect was applied in the case of "self-doped" polyanilines derivatives, when the charge 
compensation occurs at the expense of proton exchange inside the polyaniline molecule, that occurs much more faster and does not limit the rate of the redox-process [59]. The first example of the sensor based on conductivity increase of polyaniline derivative exploiting this phenomenon was recently presented in [60]. Another reason for decrease in resistance can be as follows. Properties of conducting polymers depend on where the redox-reactions with the environment occur: on the outer polymer/solution interface or within the polymer film bulk. If the reactions occur only on the polymer/solution interface without affecting the chemical composition of the bulk polymer, the oxygen from the ambience can participate in the polymer surface oxidation processes thus producing different reduced oxygen species, which can affect polymer conductivity [54].

\subsection{Chronoamperometric measurements}

Chronoamperometric measurements were performed using gold micro-electrodes to ensure that PQQ dependent enzymes can directly re-oxidise on polyAnD surface. Modification of electrode with polyAnD was performed by the same method as presented before (section 2.5). Immobilisation of enzymes by physisorption was performed on initial gold microelectrodes and on gold microelectrodes covered with polyAnD. The response of these two types of sensors to stepwise addition of enzymes substrates (1,2-propandiol for sADH, ethanol for mADH and Dglucose for GDH) were recorded. The results are presented in Fig. 8.

Modification of gold microelectrode by polyAnD with or without enzymes enhances the background current which indicates an increase of the electrode surface (curves (2) and (3)). In the absence of enzymes in the solution the background current did not change significantly (curves (1) and (2)). In the cases when the enzymes sADH and mADH were immobilised directly on gold the sensors showed response in the presence of corresponding substrate (curve (3)). The possibilities of DET from sADH and mADH to gold metal surface have been reported 
$[30,61]$. Sensors with these enzymes immobilised on polyAnD also show response to their respective substrates, which may be regarded as a confirmation that the DET also occurs in this case (curve (4)). However, sensors with the GDH adsorbed on gold electrodes showed no response in the presence of glucose (curve (3)). The response appears only if the gold microelectrode is covered by the conductive polymer layer of polyAnD (curve (4)). This fact indicates that GDH can be directly re-oxidised on polyAnD, while this process is blocked on gold surface. Thus, obtained results of chronoamperometric measurements confirm the results obtained by EIS. Moreover, taking into consideration that GDH has no heme c active site in the enzyme molecule and the behaviour of all studied enzymes is similar, it may be concluded that in these enzymes - conductive polymer systems DET occurs from the PQQ moiety. However, in the case of alcohol dehydrogenases we cannot exclude that heme $\mathrm{c}$ also participates in the electron transfer to polyAnD as this is the energetically favorable way.

\section{FIG8 here}

\section{Conclusions}

Label-free impedimetric platform based on 3D-IDEA sensor covered by new conductive polyaniline-type polyAnD polymer is proposed. Introduced impedimetric platform was applied to study biocatalysis of three different PQQ dependent enzymes. For the first time polyAnD was applied as enzyme immobilisation matrix. It was shown, that enzyme immobilisation onto polyAnD by entrapment resulted in total inactivation of enzymes, while enzymes immobilised by physisorption demonstrate specific response in the presence of the enzyme substrates with and without additional electron acceptor. Obtained results show that sADH, mADH and GDH can reoxidise on polyAnD via direct electron transfer from the enzymes active sites to the polymer 
surface. Simple amperometric method was applied to confirm these results obtained by impedance spectroscopy. Application of the EIS method for investigation of redox-enzymes in contrast to amperometric method allows for obtaining not only indirect information about processes of biocatalysis at low potential (only $25 \mathrm{mV}$ excitation potential was used during EIS experiments), but also gives information about modification of electrode surface, its structural and electrical changes. Introduced label-free impedimetric platform with PQQ dependent enzymes shows sensitivity to typical enzymes substrates at $1 \mu \mathrm{M}$ level. Based on the presented results it would be possible to design label-free impedimetric biosensors for alcohols and sugars determination. However, the improvement and nano-scale modification of polyAnD layer onto 3D-IDEA should be done to achieve higher surface area for enzyme immobilisation and to enhance sensor response.

Presented study shows that EIS method applied to interdigitated electrode structures give a useful tool for research of re-oxidation process and interaction of electroactive enzymes with various conducting materials giving information required to construct and develop analytical devices.

\section{Acknowledgement}

N. Abramova and A. Bratov acknowledge financial support from Spanish Ministry of Science and Innovation (projects AGL2008-05578-C05-05/01; IPT-2011-1055-900000 and CTQ201129163-C03-02).

E. Voitechovic would like to acknowledge the financial support from St. Petersburg State University PostDoc Grant \#12.50.1191.2014 and PhD Student Research Traineeship from the Lithuanian Science Council. 


\section{References}

[1] P. Monk, Fundamentals of Electroanalytical Chemistry, John Wiley \& Sons, Ltd.2007.

[2] A. Bratov, N. Abramova, Chemical sensors and biosensors based on impedimetric interdigitated electrode array transducers, in: D.E. Suarez (Ed.) Smart Sensor and Sensing Technology, Nova Science Publisher Inc., New York, 2013, pp. 155-164.

[3] U. Lange, N.V. Roznyatovskaya, V.M. Mirsky, Conducting polymers in chemical sensors and arrays, Anal. Chim. Acta, 614 (2008) 1-26.

[4] O.A. Sadik, A.O. Aluoch, A. Zhou, Status of biomolecular recognition using electrochemical techniques, Biosensors Bioelectron., 24 (2009) 2749-2765.

[5] B.Y. Chang, S.M. Park, Electrochemical impedance spectroscopy, Annu. Rev. Anal. Chem., 2010, pp. 207-229.

[6] P.V. Bernhardt, Enzyme electrochemistry — biocatalysis on an electrode, Aust. J. Chem., 59 (2006) 233-256.

[7] Y. Li, L. Syed, J. Liu, D.H. Hua, J. Li, Label-free electrochemical impedance detection of kinase and phosphatase activities using carbon nanofiber nanoelectrode arrays, Anal. Chim. Acta, 744 (2012) 45-53.

[8] Y. Fu, Z. Callaway, J. Lum, R. Wang, J. Lin, Y. Li, Exploiting enzyme catalysis in ultra-low ion strength media for impedance biosensing of avian influenza virus using a bare interdigitated electrode, Anal. Chem., 86 (2014) 1965-1971.

[9] A. Bratov, J. Ramon-Azcon, N. Abramova, A. Merlos, J. Adrian, F. Sanchez-Baeza, M.P. Marco, C. Dominguez, Three-dimensional interdigitated electrode array as a transducer for label-free biosensors, Biosens. Bioelectron., 24 (2008) 729-735.

[10] A. Bratov, N. Abramova, Chemical sensors and biosensors based on impedimetric interdigitated electrode array transducers, in: R.V. Harrison (Ed.) Chemical Sensors: Properties, Performance and Applications, Nova Science Publisher Inc., New York, 2010, pp. 91-115. 
[11] B. Lindholm-Sethson, J. Nystrom, M. Malmsten, L. Ringstad, A. Nelson, P. Geladi, Electrochemical impedance spectroscopy in label-free biosensor applications: multivariate data analysis for an objective interpretation, Anal. Bioanal. Chem., 398 (2010) 2341-2349.

[12] J.R. Macdonald, Impedance spectroscopy, Ann. Biomed. Eng., 20 (1992) 289-305.

[13] M. Riedel, J. Kartchemnik, M.J. Schöning, F. Lisdat, Impedimetric DNA detection-steps forward to sensorial application, Anal. Chem., 86 (2014) 7867-7874.

[14] M. Shamsipur, M. Asgari, M.F. Mousavi, R. Davarkhah, A novel hydrogen peroxide sensor based on the direct electron transfer of catalase immobilized on nano-sized NiO/MWCNTs composite film, Electroanalysis, 24 (2012) 357-367.

[15] A. Guimerà, G. Gabriel, E. Prats-Alfonso, N. Abramova, A. Bratov, R. Villa, Effect of surface conductivity on the sensitivity of interdigitated impedimetric sensors and their design considerations, Sensors Actuators B: Chem., 207, Part B (2015) 1010-1018.

[16] C. Berggren, B. Bjarnason, G. Johansson, Capacitive Biosensors, Electroanalysis, 13 (2001) 173180.

[17] A. Bratov, N. Abramova, J. Ramón-Azcón, A. Merlos, F. Sánchez-Baeza, M.P. Marco, C. Domínguez, Characterisation of the interdigitated electrode array with tantalum silicide electrodes separated by insulating barriers, Electrochem. Commun., 10 (2008) 1621-1624.

[18] A. Bratov, N. Abramova, M.P. Marco, F. Sanchez-Baeza, Three-Dimensional Interdigitated Electrode Array as a Tool for Surface Reactions Registration, Electroanalysis, 24 (2012) 69-75.

[19] R.S. Freire, C.A. Pessoa, L.D. Mello, L.T. Kubota, Direct electron transfer: an approach for electrochemical biosensors with higher selectivity and sensitivity, J. Braz. Chem. Soc., 14 (2003) 230243.

[20] D. Nelson, M. Cox, Lehninger. Principles of biochemistry, 5 ed., W. H. Freeman, New York, 2009.

[21] P. Bartlett, Bioelectrochemistry. Fundamentals, experimental techniques and applications, John Wiley \& Sons, Chichester, 2008.

[22] D. Leech, P. Kavanagh, W. Schuhmann, Enzymatic fuel cells: recent progress, Electrochim. Acta, 84 (2012) 223-234. 
Razumiene, A. Setkus, Properties of the planar ADH-dry-layer structures based on electrically controlled coupling between enzyme molecules and metal surfaces, Sensors Actuators B: Chem., 118 (2006) 60-66. [24] S. Shleev, J. Tkac, A. Christenson, T. Ruzgas, A.I. Yaropolov, J.W. Whittaker, L. Gorton, Direct electron transfer between copper-containing proteins and electrodes, Biosens. Bioelectron., 20 (2005) $2517-2554$.

[25] P. Arora, A. Sindhu, N. Dilbaghi, A. Chaudhury, Biosensors as innovative tools for the detection of food borne pathogens, Biosens. Bioelectron., 28 (2011) 1-12.

[26] K.E. Mach, P.K. Wong, J.C. Liao, Biosensor diagnosis of urinary tract infections: a path to better treatment?, Trends Pharmacol. Sci., 32 (2011) 330-336.

[27] V. Flexer, F. Durand, S. Tsujimura, N. Mano, Efficient direct electron transfer of PQQ-glucose dehydrogenase on carbon cryogel electrodes at neutral pH, Anal. Chem., 83 (2011) 5721-5727.

[28] J. Tkac, J. Svitel, I. Vostiar, M. Navratil, P. Gemeiner, Membrane-bound dehydrogenases from Gluconobacter sp.: Interfacial electrochemistry and direct bioelectrocatalysis, Bioelectrochemistry, 76 (2009) 53-62.

[29] B.L. Treu, R. Arechederra, S.D. Minteer, Bioelectrocatalysis of ethanol via PQQ-dependent dehydrogenases utilizing carbon nanomaterial supports, J. Nanosci. Nanotechnol., 9 (2009) 2374-2380.

[30] T. Ikeda, D. Kobayashi, F. Matsushita, T. Sagara, K. Niki, Bioelectrocatalysis at electrodes coated with alcohol-dehydrogenase, a quinohemoprotein with heme-c serving as a built-in mediator, J. Electroanal. Chem., 361 (1993) 221-228.

[31] V. Laurinavicius, J. Razumiene, B. Kurtinaitiene, I. Lapenaite, I. Bachmatova, L. Marcinkeviciene, R. Meskys, A. Ramanavicius, Bioelectrochemical application of some PQQ-dependent enzymes, Bioelectrochemistry, 55 (2002) 29-32.

[32] J. Razumiene, J. Barkauskas, V. Kubilius, R. Meskys, V. Laurinavicius, Modified graphitized carbon black as transducing material for reagentless H2O2 and enzyme sensors, Talanta, 67 (2005) 783-790. 
[33] J. Razumiene, A. Vilkanauskyte, V. Gureviciene, J. Barkauskas, R. Meskys, V. Laurinavicius, Direct electron transfer between PQQ dependent glucose dehydrogenases and carbon electrodes: An approach for electrochemical biosensors, Electrochim. Acta, 51 (2006) 5150-5156.

[34] W. Schuhmann, H. Zimmermann, K.V. Habermuller, V. Laurinavicius, Electron-transfer pathways between redox enzymes and electrode surfaces: reagentless biosensors based on thiol-monolayer-bound and polypyrrole-entrapped enzymes, Faraday Discuss., 116 (2000) 245-255.

[35] I.W. Schubart, G. Göbel, F. Lisdat, A pyrroloquinolinequinone-dependent glucose dehydrogenase (PQQ-GDH)-electrode with direct electron transfer based on polyaniline modified carbon nanotubes for biofuel cell application, Electrochim. Acta, 82 (2012) 224-232.

[36] P.K. Ivanova-Mitseva, V. Fragkou, D. Lakshmi, M.J. Whitcombe, F. Davis, A. Guerreiro, J.A. Crayston, D.K. Ivanova, P.A. Mitsev, E.V. Piletska, S.A. Piletsky, Conjugated polymers with pendant iniferter units: versatile materials for grafting, Macromolecules, 44 (2011) 1856-1865.

[37] S. Nambiar, J.T.W. Yeow, Conductive polymer-based sensors for biomedical applications, Biosens. Bioelectron., 26 (2011) 1825-1832.

[38] S. Ameen, M.S. Akhtar, M. Husain, Polyaniline and its nanocomposites: synthesis, processing, electrical properties and applications, Sci. Adv. Mater., 2 (2010) 441-462.

[39] P. Novak, K. Muller, K.S.V. Santhanam, O. Haas, Electrochemically active polymers for rechargeable batteries, Chem. Rev., 97 (1997) 207-281.

[40] K. Grennan, A.J. Killard, C.J. Hanson, A.A. Cafolla, M.R. Smyth, Optimisation and characterisation of biosensors based on polyaniline, Talanta, 68 (2006) 1591-1600.

[41] W. Wongsan, W. Aeungmaitrepirom, O. Chailapakul, W. Ngeontae, T. Tuntulani, Bifunctional polymeric membrane ion selective electrodes usingphenylboronic acid as a precursor of anionic sites and fluoride as aneffector: A potentiometric sensor for sodium ion and an impedimetricsensor for fluoride ion, Electrochim. Acta, 111 (2013) 234-241.

[42] J. Janata, M. Josowicz, Conducting polymers in electronic chemical sensors, Nat. Mater., 2 (2003) 19-24. 
[43] G.P. Kittlesen, H.S. White, M.S. Wrighton, Chemical derivatization of microelectrode arrays by oxidation of pyrrole and $\mathrm{N}$-methylpyrrole: fabrication of molecule-based electronic devices, J. Am. Chem. Soc., 106 (1984) 7389-7396.

[44] E.W. Paul, A.J. Ricco, M.S. Wrighton, Resistance of polyaniline films as a function of electrochemical potential and the fabrication of polyaniline-based microelectronic devices, J. Phys. Chem., 89 (1985) 1441-1447.

[45] J.W. Thackeray, M.S. Wrighton, Chemically responsive microelectrochemical devices based on platinized poly(3-methylthiophene): variation in conductivity with variation in hydrogen, oxygen, or $\mathrm{pH}$ in aqueous solution, J. Phys. Chem., 90 (1986) 6674-6679.

[46] D.T. Hoa, T.N.S. Kumar, N.S. Punekar, R.S. Srinivasa, R. Lal, A.Q. Contractor, Biosensor based on conducting polymers, Anal. Chem., 64 (1992) 2645-2646.

[47] H. Sangodkar, S. Sukeerthi, R.S. Srinivasa, R. Lal, A.Q. Contractor, A biosensor array based on polyaniline, Anal. Chem., 68 (1996) 779-783.

[48] N.G. Skinner, E.A.H. Hall, Investigation of the origin of the glucose response in a glucose oxidase vertical bar polyaniline system, J. Electroanal. Chem., 420 (1997) 179-188.

[49] D. Lakshmi, M.J. Whitcombe, F. Davis, I. Chianella, E.V. Piletska, A. Guerreiro, S. Subrahmanyam, P.S. Brito, S.A. Fowler, S.A. Piletsky, Chimeric polymers formed from a monomer capable of free radical, oxidative and electrochemical polymerisation, Chem. Commun., 0 (2009) 2759-2761.

[50] D. Lakshmi, A. Bossi, M.J. Whitcombe, I. Chianella, S.A. Fowler, S. Subrahmanyam, E.V. Piletska, S.A. Piletsky, Electrochemical sensor for catechol and dopamine based on a catalytic molecularly imprinted polymer-conducting polymer hybrid recognition element, Anal. Chem., 81 (2009) 3576-3584.

[51] L. Marcinkeviciene, I. Bachmatova, R. Semenaite, R. Rudomanskis, G. Brazenas, R. Meskiene, R. Meskys, Purification and characterisation of alcohol dehydrogenase from Gluconobacter sp. 33, Biologija, 2 (1999) 6.

[52] H. Toyama, Z.W. Chen, M. Fukumoto, O. Adachi, K. Matsushita, F.S. Mathews, Molecular cloning and structural analysis of quinohemoprotein alcohol dehydrogenase ADH-IIG from Pseudomonas putida HK5, J. Mol. Biol., 352 (2005) 91-104. 
[53] P. Dokter, J.T. Pronk, B.J. van Schie, J.P. van Dijken, J.A. Duine, The in vivo and in vitro substrate specificity of quinoprotein glucose dehydrogenase of Acinetobacter calcoaceticus LMD79.41, FEMS Microbiol. Lett., 43 (1987) 195-200.

[54] A. Malinauskas, R. Holze, An in situ spectroelectrochemical study of redox reactions at polyanilinemodified ITO electrodes, Electrochim. Acta, 43 (1998) 2563-2575.

[55] Z. Mandić, L. Duić, Polyaniline as an electrocatalytic material, J. Electroanal. Chem., 403 (1996) 133-141.

[56] L. Marcinkeviciene, J. Stankeviciute, I. Bachmatova, R. Vidziunaite, A. Chaleckaja, R. Meskys, Biocatalytic properties of quinohemoprotein alcohol dehydrogenase IIG from Pseudomonas putida HK5, Chemija, 23 (2012) 223-232.

[57] V.L. Davidson, Electron transfer in quinoproteins, Arch. Biochem. Biophys., 428 (2004) 32-40.

[58] A. Oubrie, Structure and mechanism of soluble glucose dehydrogenase and other PQQ-dependent enzymes, BBA-Proteins Proteomics, 1647 (2003) 143-151.

[59] A. Malinauskas, Self-doped polyanilines, J. Power Sources, 126 (2004) 214-220.

[60] E.A. Andreyev, M.A. Komkova, V.N. Nikitina, N.V. Zaryanov, O.G. Voronin, E.E. Karyakina, A.K. Yatsimirsky, A.A. Karyakin, Reagentless Polyol Detection by Conductivity Increase in the Course of Self-Doping of Boronate-Substituted Polyaniline, Anal. Chem., 86 (2014) 11690-11695.

[61] A. Setkus, A. Galdikas, V. Laurinavicius, R. Meskys, A. Mironas, J. Razumiene, Electric charge transport in the symmetric metal-enzyme junctions affected by biochemical interaction, Colloids Surf. Physicochem. Eng. Aspects, 249 (2004) 141-143. 


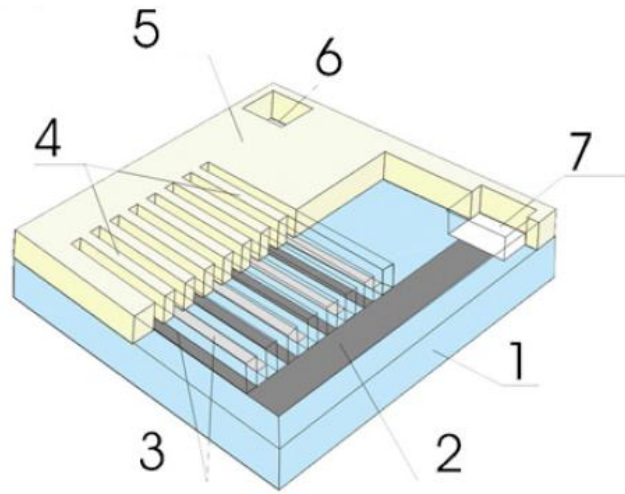

Fig. 1. Design of 3D-IDEA sensor. (1) Insulating substrate $\left(\mathrm{Si} / \mathrm{SiO}_{2}\right),(2)$ electrode collector bar, (3) electrode digits, (4) silicon dioxide barriers between the electrode digits, (5) $4 \mu \mathrm{m}$ thick $\mathrm{SiO}_{2}$ layer, and (6 and 7) aluminium contact pads.

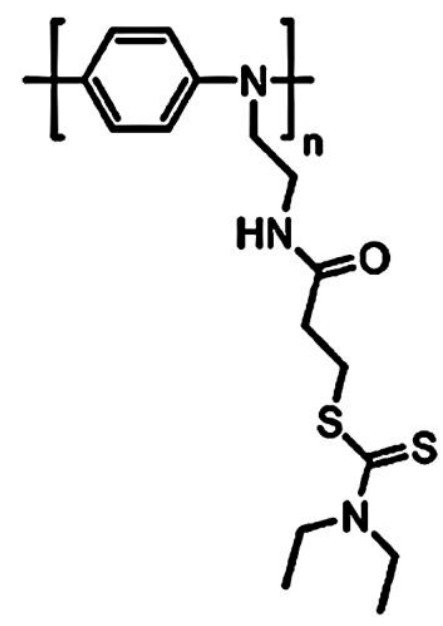

\section{Fig. 2. PolyAnD structure.}


A

(1)

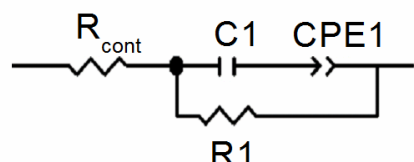

(2)

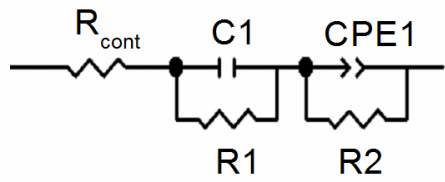

B

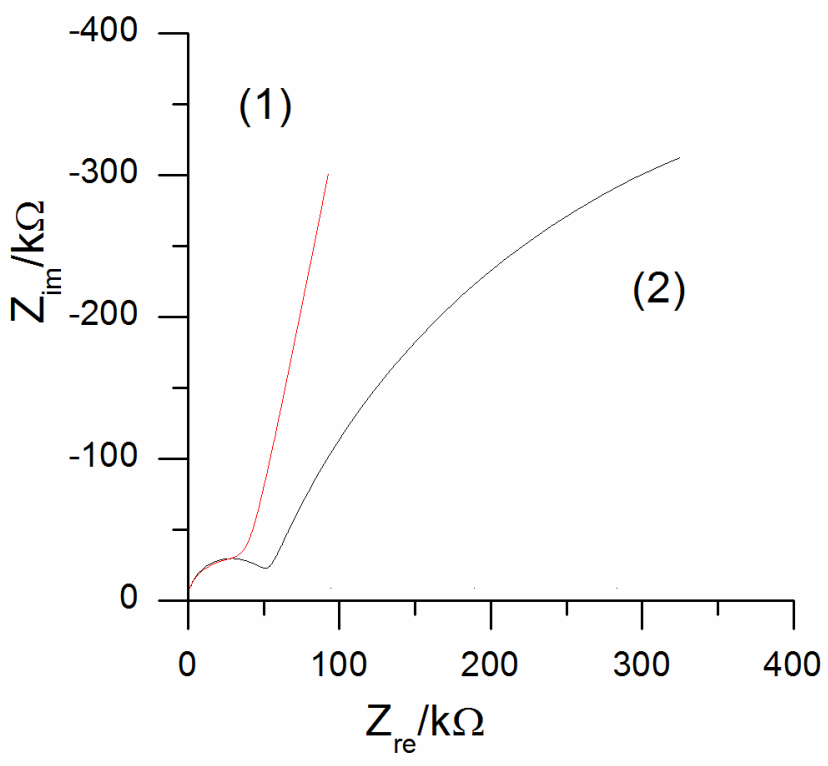

Fig. 3. Equivalent circuits of a 3D-IDEA sensor. A - Equivalent circuit models (1) and (2). B

- Nyquist plot shows characteristic impedance spectra for these two equivalent circuits. 


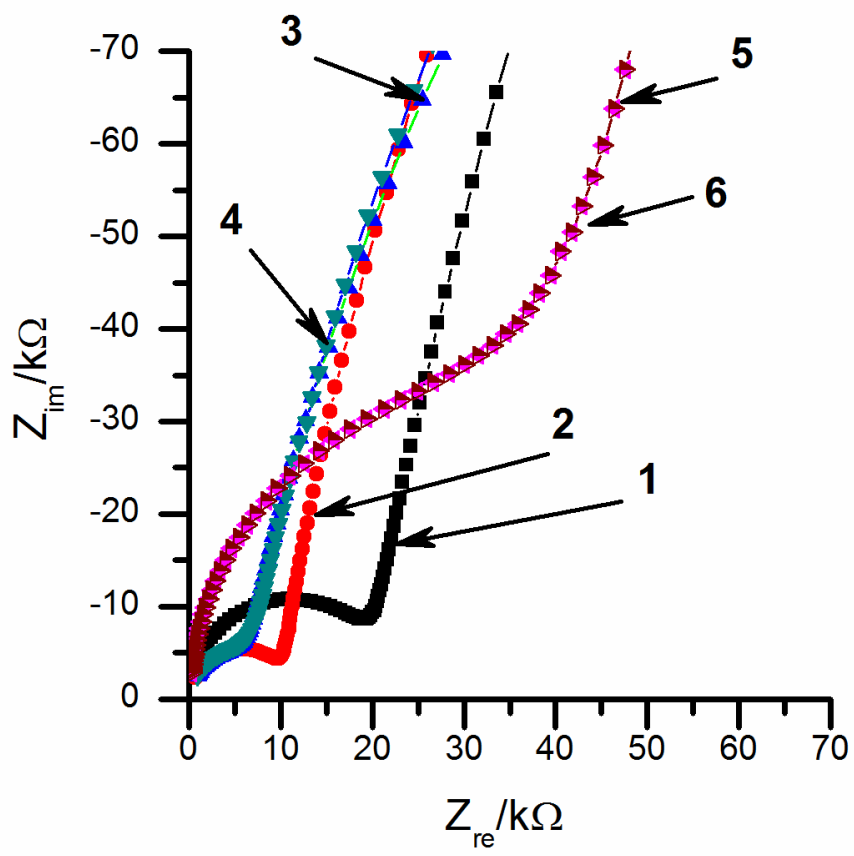

Fig. 4. The Nyquist plot of the impedance spectra of 3D-IDEA sensor modified by polyAnD and PQQ dependent enzyme in $\mathbf{C a C l}_{2}$ solutions with different conductivity. The curves 1 and 2 represent spectra of an initial clean 3D-IDEA sensor; 3 and 4 - modified by polyAnD; 5 and 6 - modified by polyAnD and the adsorbed enzyme. Curves 1,3 and 5 were obtained in $10^{-5}$ $\mathrm{M} \mathrm{CaCl}_{2}(4.62 \mu \mathrm{S} / \mathrm{cm})$. Spectra 2, 4 and 6 were measured in $5 \cdot 10^{-5} \mathrm{M} \mathrm{CaCl}_{2}$ with $16.8 \mu \mathrm{S} / \mathrm{cm}$ conductivity 
Fig. 5. The resistance of modified by polyAnD 3D-IDEA sensor dependence of solution redox-potential. Dash line represents linear fitting of data points $\left(r^{2}=0.9734\right)$.
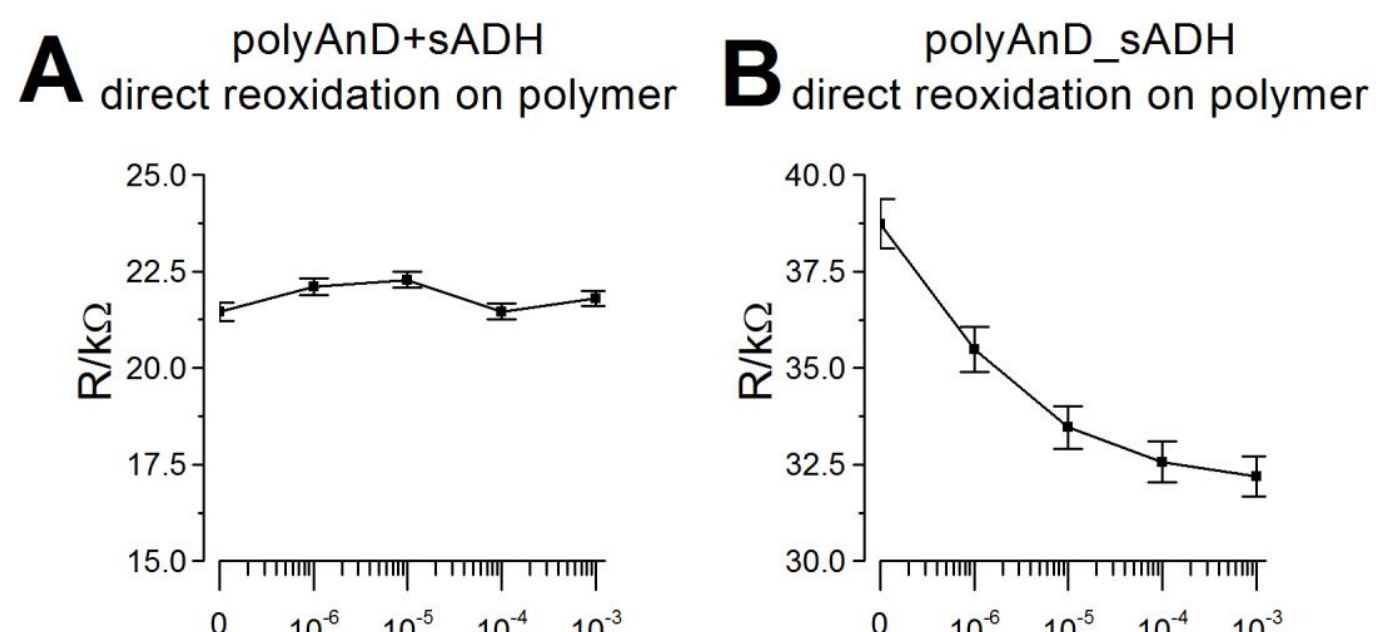

$\log (\mathrm{c}(1,2$-propandiol $)) / \mathrm{mol} \mathrm{dm}^{-3} \log (\mathrm{c}(1,2$-propandiol $)) / \mathrm{mol} \mathrm{dm}^{-3}$

Fig. 6. Response of modified by polyAnD sensor with immobilized SADH to addition of 1,2propandiol. Response of $\mathbf{A}$ - entrapped and $\mathbf{B}$ - adsorbed sADH to addition of substrate without soluble electron acceptor. 

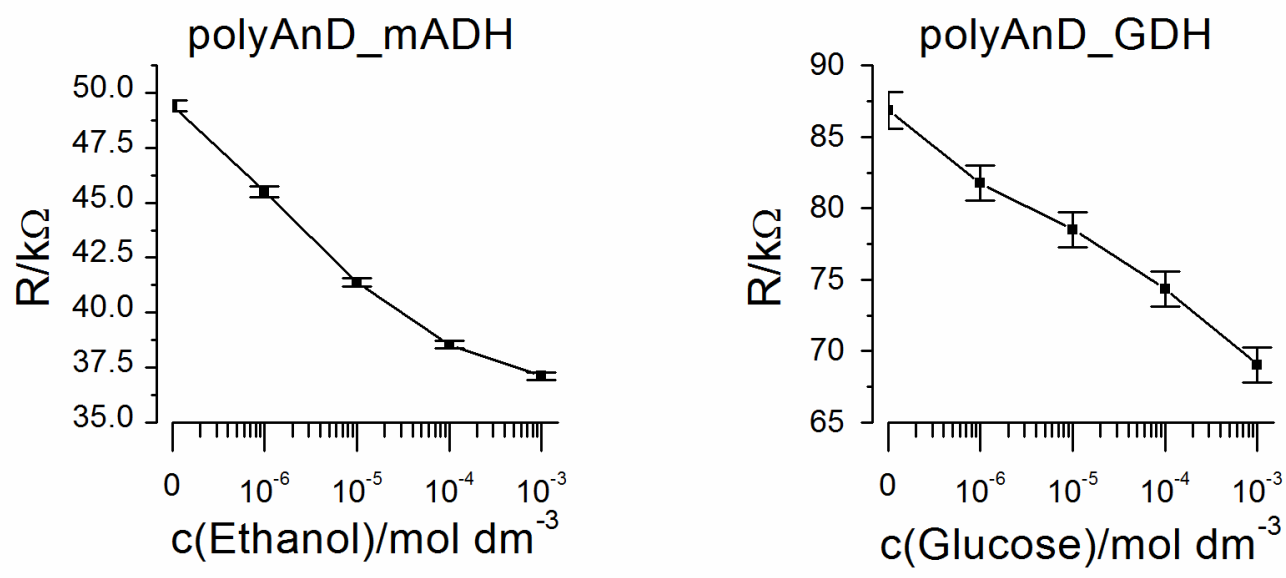

Fig. 7. Response of polyAnD modified sensor with adsorbed mADH (left) and GDH (right) to addition of enzymes substrates, ethanol and glucose, respectively.
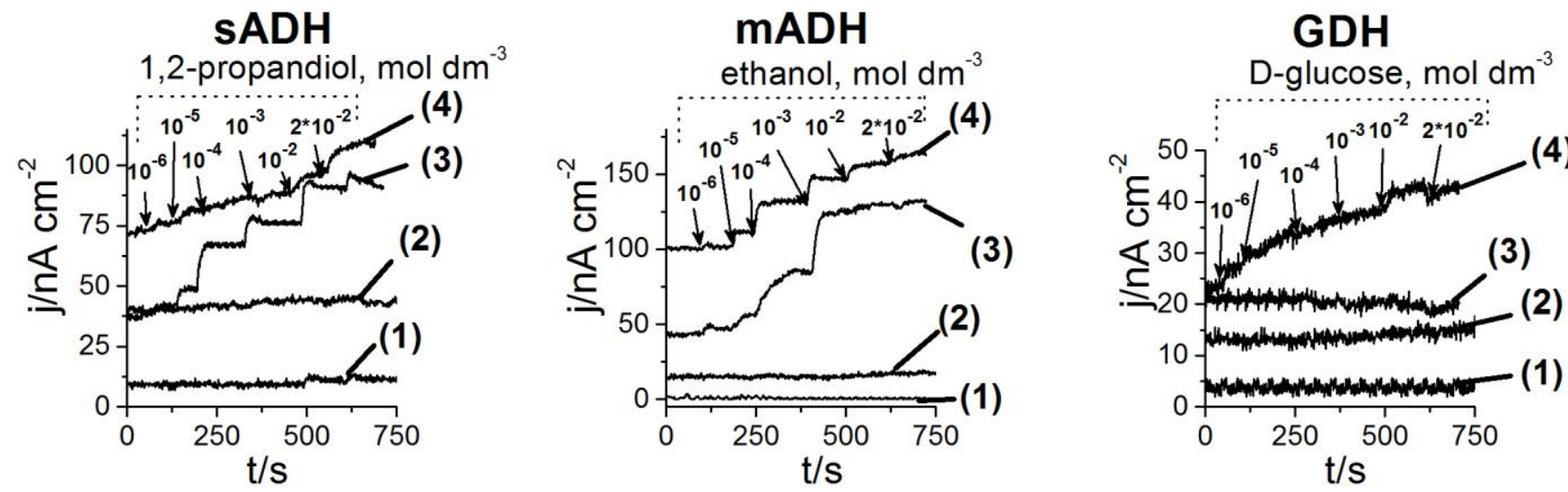

Fig. 8. Chronoamperometric measurements of gold electrodes with PQQ dependent enzymes and polyAnD. (1) - chronoamperogram of clean gold microelectrode, (2) chronoamperogram after modification with polyAnD, (3) - chronoamperogram after modification with enzyme and (4) - chronoamperogram of gold microelectrode, which was modified by polyAnD and enzyme. The numbers in each graph show concentration of the corresponding enzyme substrate $(\mathrm{M})$ after stepwise addition. 